Article

\title{
Identification and characterization of biosynthetic gene clusters from halophilic marine fungus Eurotium rubrum
}

Obul Reddy Bandapali', Jens Frederik Teilfeldt Hansen'2, Alisha Parveen ${ }^{3}$, Pradeep Phule, Emmagouni Sharath Kumar Goud", Suraj Kumar Acharya ${ }^{6}$, Jens Laurids Sørensen ${ }^{7}$ \& Abhishek Kumar $^{8, *}$

${ }^{1}$ Division of Pediatric Neurooncology, German Cancer Research Center (DKFZ), German Cancer Consortium (DKTK), Hopp Children's Cancer Center (KiTZ), and Heidelberg University, Medical Faculty, D-69120 Heidelberg, Germany; o.bandapalli@dkfz-heidelberg.de

2Department of Biochemistry, McGill University, Montréal, QC H3G 0B1, Canada and Department of Chemistry and Bioscience, Aalborg University, Niels Bohrs Vej 8, DK-6700 Esbjerg, Denmark; jens.hansen@mail.mcgill.ca

${ }^{3}$ Institute of Molecular Medicine and Cell Research, Albert Ludwigs University Freiburg, Stefan Meier Strasse 17, 79104, Freiburg, Germany; alisha.parveen@uniklinik-freiburg.de

4Institute of Bioinformatics, International Technology Park, Bangalore, 560066 India;pradeep@ibioinformatics.org

5Institute of Bioinformatics, International Technology Park, Bangalore, 560066 India; sharath@ibioinformatics.org ${ }^{6}$ Institute of Bioinformatics, International Technology Park, Bangalore, 560066 India; suraj@ibioinformatics.org

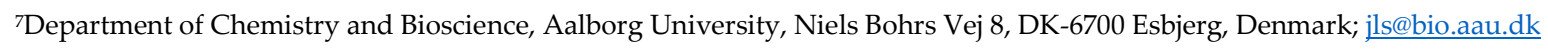
${ }^{8}$ Institute of Bioinformatics, International Technology Park, Bangalore, 560066 and Manipal Academy of Higher Education (MAHE), Manipal 576104, Karnataka, India; abhishek@ibioinformatics.org

* Correspondence: abhishek@ibioinformatics.org; Tel.: +91 80-2841-6140 (A.K.) 


\begin{abstract}
Eurotium rubrum is a halophilic marine ascomycete, which can bear the hypersalinities of the Red Sea and proliferate, while most living entities cannot bear this condition. Recently, a $26.2 \mathrm{Mb}$ assembled genome of this fungus had become available. Marine fungi are fascinating organisms capable of harboring several biosynthetic gene clusters (BGCs), which enables them to produce several natural compounds with antibiotic and anticancerous properties. Understanding the BGCs are critically important for the development of biotechnological applications and the discovery of future drugs. There is no knowledge available on the BGCs of this halophilic marine ascomycete. Herein, we set out to explore and characterize BGCs and the corresponding genes from E. rubrum using bioinformatic methods. We deciphered 36 BGCs in the genome of E. rubrum. These 36 BGCs can be grouped into four non-ribosomal peptide synthetase (NRPS) clusters, eight NRPS-like (NRPSL) BGCs, eight type I polyketide synthase (T1PKS), 10 terpene BGCs including one $\beta$-lactone cluster, four hybrid BGCs, and two siderophore BGCs. This study is an example of marine genomics application into potential future drug-like compound discovery.
\end{abstract}

Keywords: Biosynthetic gene clusters; Eurotium rubrum; halophilic; marine genomics; nonribosomal peptide synthetase; T1pks; Terpene;

\title{
1. Introduction
}

The Dead Sea is an excellent niche for testing the survival skills of many living organisms because it is the most hypersaline habitats on our planet [1]. The brines of the Dead Sea has a salinity level upto $348 \mathrm{~g} \mathrm{l-1}$ [1]. This makes it unbearable for most of the living entities, so the majority of species living here stay in their dormant stages to survive this hypersality and they return to the normal stages during reduced salinity either by rare heavy flooding events [2] or by underwater fresh water springs [3]. Only a limited number of organisms survive during the conditions of hypersalinity like halobacteria, Dunaliella parva Lerche (a green algae) and some species of fungi. One of these fungi is the ascomycete Eurotium rubrum, which survive in the Red sea. Recently the genome of this marine fungus has become available with a genome size of $26.2 \mathrm{Mb}$ [4]. Generally, marine fungi are considered as an excellent source of bioactive compound and their genomes harbors many biosynthetic gene clusters (BGCs) from which these natural compounds are produced [5-8]. One of the best examples of marine fungi producing such beneficial compounds is Scopulariopsis producing the anti-cancerous scopularide [5]. Herein, our aim is to unravel the BGCs of the halophilic marine fungus E. rubrum using the recently available genome. We also carried out extensive characterization of these BGCs and corresponding genes producing natural compounds. We identified 36 BGCs in the E. rubrum genome and we designated them as EruBGC1 to EruBGC36, which are classified into four nonribosomal peptide synthetase (NRPS) clusters, eight each NRPS-like (NRPSL) BGC and T1PKS, 10 terpene BGCs, four hybrid BGCs, and two siderophore BGCs. 


\section{Results \& Discussion}

\subsection{Overview of BGCs of E. rubrum genome}

We identified 36 biosynthetic gene clusters (BGCs) in the $26.2 \mathrm{Mb}$ assembled genome of E. rubrum. These 36 clusters are designated as EruBGC1 to EruBGC36 (Tables 1-5), and this list has four nonribosomal peptide synthetase (NRPS) clusters (Table 1), eight each NRPS-like (NRPSL) BGC (Table 2 ) and T1PKS (Table 3), ten terpene BGCs including $\beta$-lactone producing BGC (Table 4), four hybrid BGCs (Table 5) and two siderophore BGCs (Table 6). The hybrid BGCs consist of four different clusters, namely, NRPS, indole (EruBGC7), T1PKS, indole (EruBGC17), T1PKS,NRPS-like (EruBGC28) and T1PKS,NRPS (EruBGC30, Table 5).

\subsection{Summary of BGCs encoding NRPS from E. rubrum}

There are four BGCs in the genome of E. rubrum, which encode NRPS genes and corresponding proteins (Table 1). The cluster EruBGC2 is localized on the scaffold00002 (KK088412.1) spanning in about $58 \mathrm{~kb}$ region from 40,834-98,875 bp (Table 1). This cluster has 18 genes in total with core NRPS gene as EURHEDRAFT_469898 and this BGC is conserved with top hits are in genomes of Saccharopolyspora flava, two species of Gordonia and Streptomyces sp.(Fig. S1). The core NRPS protein (nonribosomal siderophore peptide synthase SidC, GenBank ID - EYE98782.1) of this BGC is 4734 amino acid long, sharing sequence identities $93 \%$ and $65 \%$ each with orthologs from Aspergillus cristatus , A. flavus (strain NRRL3357) and A. oryzae (strain 3.042), respectively (Fig. 1B).

The second NRPS cluster (EruBGC14) contents 13 genes with size of $43.1 \mathrm{~kb}$ on the scaffold00008 (KK088418.1) ranged from 5,62,619 bp to 6,05,729 bp (Table 1). It has no homology with any clusters in sequenced genomes (Fig. S1). The core NRPS protein (EYE96553.1) of this BGC is known as acetylCoA synthetase-like protein with length of 1037 amino acids long chain and it shares sequence identities $55 \%$ and $38 \%$ with AMP-dependent synthetase/ligase (CRL27778.1) and NRPS (XP_754251.1) from Penicillium camemberti and Aspergillus fumigatus, respectively (Fig. 1B).

EruBGC25 is the third NRPS cluster that localized on the the scaffold00034 (KK088444.1) harboring 14 genes within $46.2 \mathrm{~kb}$ (Table 1). This BGC show similarities with clusters of multiple strains of Pseudomonas, Photorhabdus temperata and Bradyrhizobium yuanmingense (Fig. S1). The core protein of this cluster is NRPS6 (EYE91538.1) with 6 protein domains (Fig. 1A) and several annotated hits in different Aspergillus genome (Fig. 1A). The fourth NRPS cluster (EruBGC32) resides on the scaffold00058 is $33.5 \mathrm{~kb}$ long with total of 14 genes (Table 1). It shows homologies with NRPS clusters from Chitinophaga eiseniae, Myxococcus xanthus and Archangium violaceum $\mathrm{Cb}$, respectively (Fig. S1). It has five core genes (Table 1), which encodes for NRPS proteins namely EYE90154.1, EYE90155.1, EYE90156.1, EYE90157.1 and EYE90158.1 (Fig. 1E) with at least three domains as adenylation, peptidyl carrier protein and condensation (Fig 1).

\subsection{There are 8 NRPS-like BGCs in the E. rubrum genome}

We identified eight NRPS-like BGCs (Table 2). The first NRPS-like BGC is EruBGC4, which is mapped to a $41.2 \mathrm{~kb}$ region on the scaffold00003 (KK088413.1) with total 19 genes (Table 2). This cluster has homologs in three bacteria namely Acetivibrio cellulolyticus, Xanthobacter autotrophicus and Frankia species (Fig. S2A). The core protein of EruBGC4 is acetyl-CoA synthetase-like protein (EYE98346.1) with NRPS domains (Fig. 1) and several annotated hits during homology detection (Fig. 
S3A). The second NRPS-like BGC (EruBGC10) is located in the $\sim 42 \mathrm{~kb}$ on the scaffold00005 (KK088415.1) with 17 genes (Table 2). EruBGC10 has hits in several bacterial genomes with top are Desulfovibrio ferrireducens, Salinispora arenicola and Nostoc linckia (Fig. S2B). The core enzyme of this cluster is hypothetical protein (EYE97683.1), however it has NRPS domains (Fig. 1) and we found several annotated hits as NRPS-like proteins from Aspergillus strains (Fig. S3B).

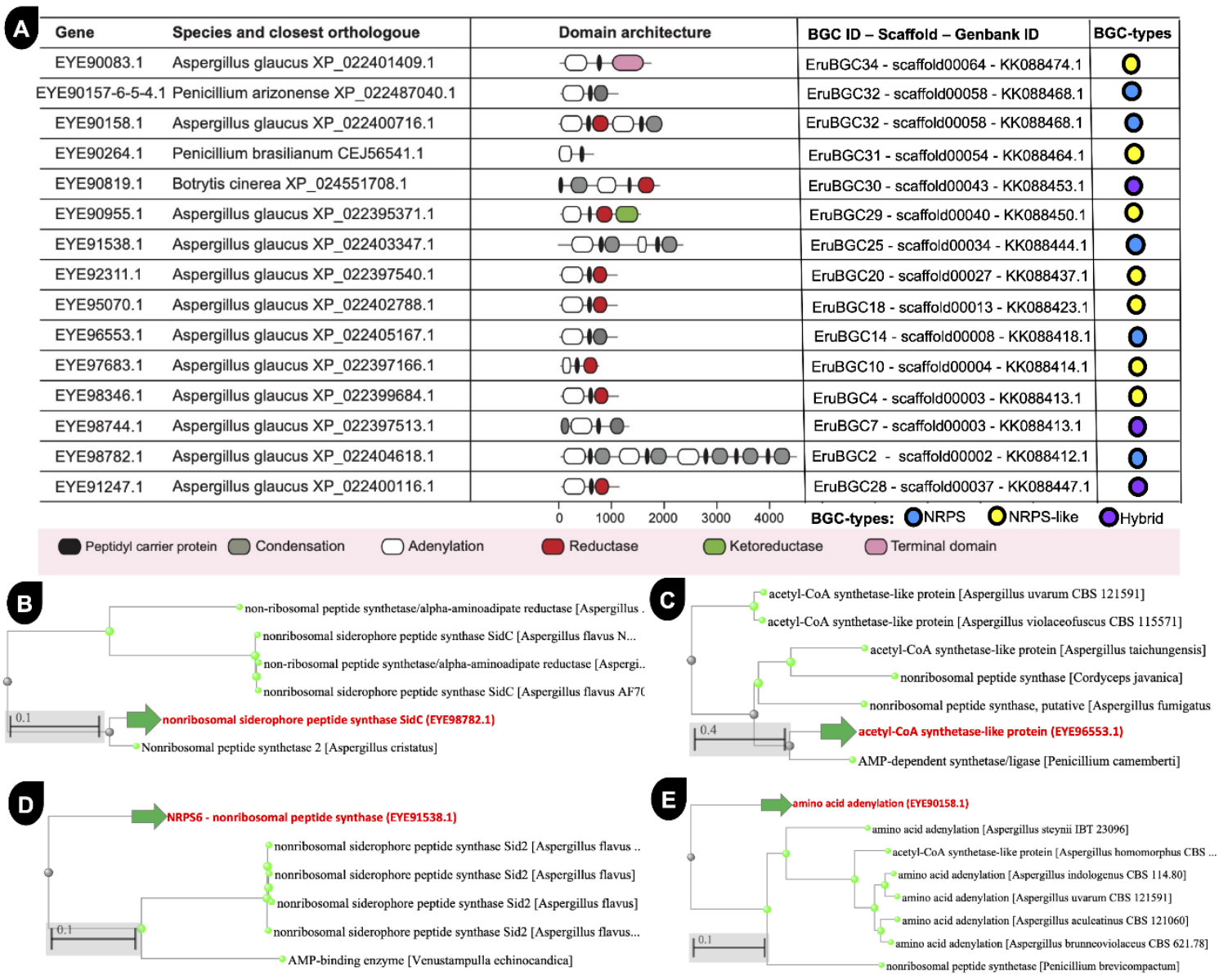

Fig 1. Summary of non-ribosomal peptide synthetase (NRPS).

A. Overview of protein domain of NRPS and NRPS-like BGCs of marine E. rubrum.

B-E - Re-annotation and phylogenetic analyses of core NRPS proteins

The third NRPS-like BGC (EruBGC18) is mapped to the scaffold00013 (KK088423.1) in a $43.2 \mathrm{~kb}$ region $(1,25,819 \mathrm{bp}-1,69,069 \mathrm{bp})$, which harbors 11 genes (Table 2). This BGC has no homologous clusters (Fig. S2C). The core protein of this cluster (EYE95070.1) is known as a putative NRPS-like enzyme and it is 1048 residues long. It shares $78 \%$ of sequence identities each with linear gramicidin synthase subunit D (GAO87904.1) from A. udagawae, putative NRPS-like enzyme (EDP49425.1) from A. fumigatus A1163 and a putative NRPS-like enzyme (XP_001257972.1) from A. fischeri NRRL 181 (Fig. S3C). The fourth NRPS-like BGC, EruBGC20 is localized on the scaffold00027 (KK088437.1) with 12 genes in a region of $34.6 \mathrm{~kb}$ (Table 2). EruBGC20 has no homologous clusters in the public databases (Fig. S2D). The core protein of this cluster (EYE92311.1) is known as an NRPS-like enzyme and it is 1045 residues long. This protein shares 59\% and 56\% identities with putative NRPS-like 
enzymes of $A$. clavatus NRRL 1 (XP_001268898.1) and A. bombycis (OGM48478.1), respectively (Fig. S3D).

The fifth NRPS-like BGC, EruBGC22 is $\sim 44 \mathrm{~kb}$ long on scaffold00028 from 1,36,752 bp to 1,81,201 bp harboring 18 genes (Table 2). EruBGC22 has homologous clusters in strains of Aspergillus, Trichophyton, Exophiala dermatitidis, Botryotinia fuckeliana, Leptosphaeria maculans and Colletotrichum higginsianum (Fig. S2E). Top 2 hits of EruBGC22 are AP007155.1_c2 from Aspergillus oryzae RIB40 (42\% identities) and AM270078.1_c1 from A. niger contig (35\% identities). This BGC is capable of producing four dehydrogenases like aryl-alcohol dehydrogenase (EYE92212.1), L-aminoadipatesemialdehyde dehydrogenase (EYE92214, Fig. S3D), xanthine dehydrogenase (EYE92216.1) and aldehyde dehydrogenase (EYE92219.1). The core protein of this cluster has 1426 residues (EYE92214) with $83 \%, 80 \%$ and $70 \%$ sequence identities with L-aminoadipate-semialdehyde dehydrogenases of A. oryzae (OOO09926.1) and A. udagawae (GAO83448.1) and Male sterility, NAD-binding of $P$. griseofulvum (KXG50863.1).This protein is a key intermediate compound in $\Delta^{1}$-piperideine-6carboxylic acid (P6C) [9]. As per L-lysine degradation pathway, it is catalyzed as a product of saccharopine by Saccharopine dehydrogenase (SDH, EC:1.5.1.-). Hence, it is a major component of pathway of swainsonine synthesis and swainsonine has anticancerous and immune regulatory roles [10]. Additionally, this BGC is also carrying a gibberellin 3-beta hydroxylase (EYE92206.1), which shares $87 \%$ identities with isopenicillin N synthase (CRL25624.1) from Penicillium camemberti.

The sixth NRPS-like BGC (EruBGC29) is mapped to scaffold00040 in a $~ 36 \mathrm{~kb}$ region with 9 genes in this BGC (Table 2). This BGC has counterparts in both bacteria (Mycobacterium marinum, Rhodococcus and Streptomyces strains) and ascomycetes (Aspergillus strains, Fig. S2F). This core protein of EruBGC29 is putative NRPS-like protein (EYE90955.1), which is 1292 amino acid long. This protein shares $82 \%$ and $81 \%$ of sequence identities with gramicidin synthase subunit D (OKP10752.1) from P. subrubescens and AMP-dependent synthetase/ligase (CDM33966.1) from P. roqueforti FM164 (Fig. S3G). The seventh NRPS-like cluster (EruBGC31) has 12 genes and it is located in the scaffold00054 (KK088464.1) with the fragment size of 41.7kb. This cluster has homologs in several bacteria namely Chitinophaga eiseniae, Myxococcus xanthus and strains of Archangium and Streptomyces (Fig. S2G). EruBGC31 is encoding for acetyl-CoA synthetase-like protein (EYE90264.1) as core enzyme with two NRPS domains (Fig 1) and annotated hits in Penicillium brasilianum and Trichophyton (Fig. S3G). The eighth NRPS-like BGC, EruBGC34 is the fifth BGC found on scaffold00064 (KK088474.1), spanning seven genes in $30.1 \mathrm{~kb}$ region (Table 2). We do not detect any fungal homologous clusters in public databases for EruBGC34, however there is only one known bacterial BGC in Streptomyces celluloflavus strain NRRL B-2493 (Fig. S2H). Acetyl-CoA synthetase-like protein (EYE90083.1, 1653 residues) with conserved protein domains (Fig 1) is the core protein of EruBGC34 with top 2 known homologs being AMP-dependent synthetase/ligase (OQE47426.1/80\% identity) from P. griseofulvum and AMP-dependent synthetase/ligase (XP_016602600.1/79\%) from P. expansum (Fig. S3H).

\subsection{Summary of T1pks producing BGCs from E. rubrum}

There are eight BGCs in the genome of E. rubrum, which encode T1pks genes (Table 3) and corresponding proteins are listed in Fig 2 with their protein domains. The first T1PKS cluster EruBGC3 is localized on the scaffold00002 (KK088412.1) in a region of $47.8 \mathrm{~kb}$ and it harbors 18 genes (Table 3). This BGC has homologous BGCs in several strains of Mycolicibacterium and Kitasatospora aureofacien, respectively (Fig. S4A). 
A. Domain structures of PKS proteins

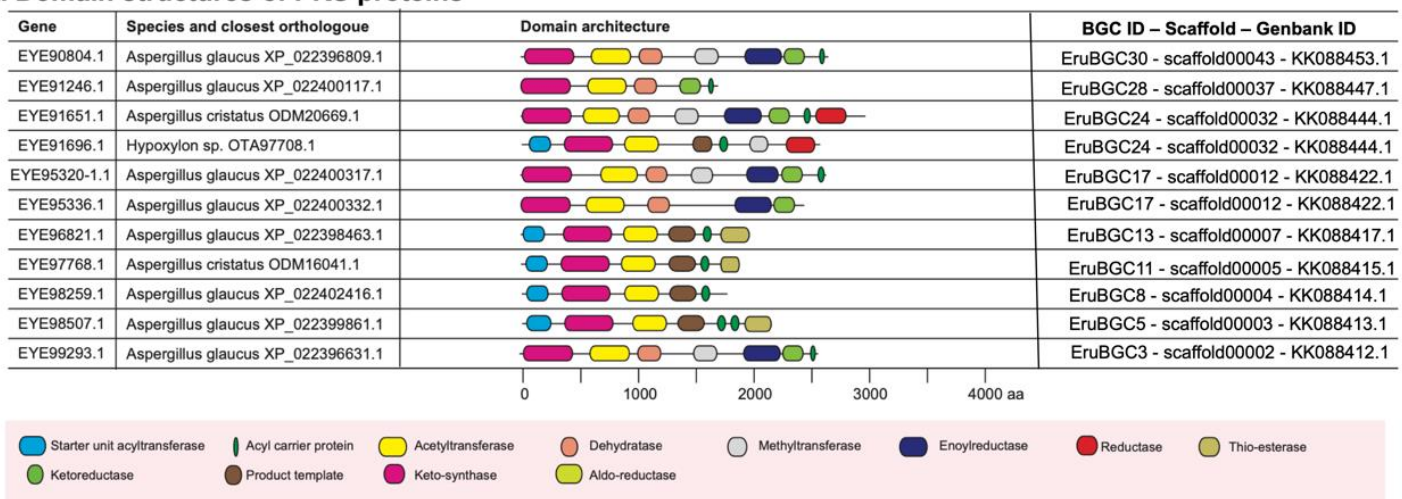

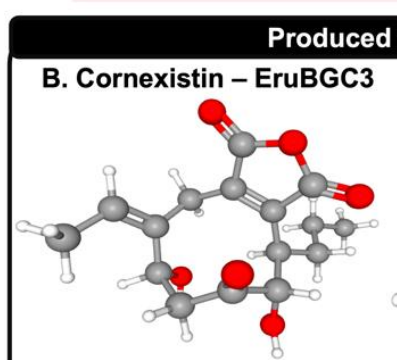

MF: $\mathrm{C}_{16} \mathrm{H}_{20} \mathrm{O}_{6} \quad$ MW: $308.33 \mathrm{~g} / \mathrm{mol}$

C. Naphthopyrone- EruBGC5

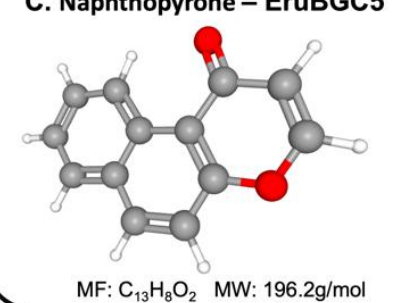

from PKS-based BGCs

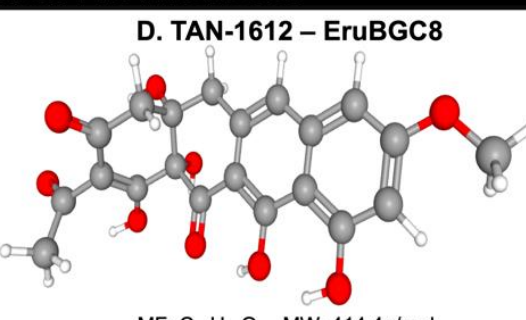

MF: $\mathrm{C}_{21} \mathrm{H}_{18} \mathrm{O}_{9} \quad$ MW: $414.4 \mathrm{~g} / \mathrm{mol}$

E. Asperfuranone - EruBGC24

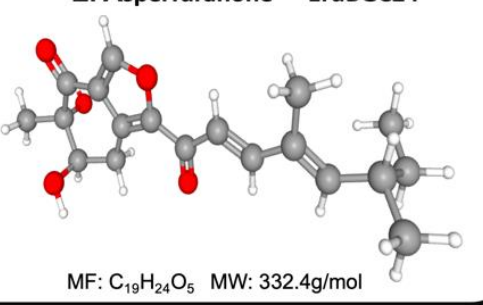

Produced from hybrid BGCs

F. Epipyriculol - EruBGC12

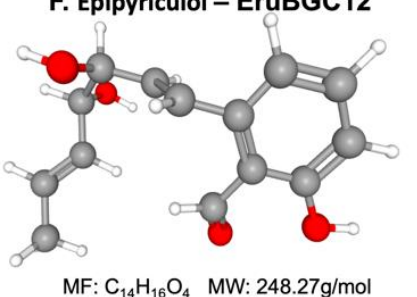

G. Asperlactone - EruBGC28

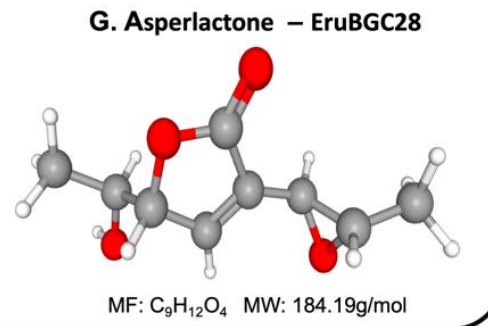

Fig 2. Summary of protein domains in PKS encoding by marine E. rubrum.

The core protein is putative polyketide synthase with different PKS domains (EYE99293.1, Fig 2) and upon homology detection, it has several hits with annotation as PKS proteins (Fig. S5A). This BGC is similar to cornexistin BGCs (Fig. S4A) from Paecilomyces divaricatus (MIBiG ID - BGC0001436 and BGC0001557). This suggested that this BGC is potent producer of cornexistin (molecular formula $\mathrm{C}_{16} \mathrm{H}_{20} \mathrm{O}_{6}$, Fig 2), which has herbicidal activity. The second T1PKS cluster, EruBGC5 is locate on scaffold00003 (KK088413.1) with a size of 46.7kb and this fragment has 14 genes (Table 3). EruBGC5 has homologs in several bacterial genomes including several Streptomyces species (Fig. S4B). The core protein of EruBGC5 is polyketide synthetase PksP (EYE98507.1, Fig 2) and it has annotated hits from several Aspergillus strains (Fig. S5B). This BGC is capable of producing naphthopyrone as this cluster has similarities with naphthopyrone cluster (MIBiG ID - BGC0000107) from Aspergillus nidulans FGSC A4 (Fig. S4B). The third T1pks BGC (EruBGC8) has a size of $45.4 \mathrm{~kb}$ on the scaffold00004 (KK088414.1) with 20 genes (Table 3), which is similar to piericidin A1 and aflatoxin BGCs from Streptomyces piomogenus and Aspergillus ochraceoroseus, respectively (Fig. S4C). The core protein is polyketide synthetase with several PKS-based domains (EYE98259.1, Fig 2) and it has homologs in several Aspergillus species (Fig. S5C). This cluster is capable of producing desmethyl TAN-1612 $\left(\mathrm{C}_{21} \mathrm{H}_{18} \mathrm{O}\right.$, Fig 2), which harbors a tetracyclic naphthacenedione core structure. The fourth T1PKS cluster (EruBGC11) is mapped on the scaffold00005 (KK088415.1) with 18 genes within a 46kb fragment (Table 3). This fragment has homologous BGCs in several bacterial strains like Kamptonema formosum, 
Streptomyces bingchenggensis and Nocardia veterana (Fig. S4C). The core enzyme of EruBGC11 is polyketide synthase (EYE97768.1) with multiple PKS domains (Fig 2) plus annotated hits to multiple Aspergillus strains (Fig. S5D). The fifth T1pks-BGC (EruBGC13) is located on the scaffold00007 (KK088417.1) with 15 genes in a region of 46.3kb (Table 3). PKS16 protein (EYE96821.1) is the backbone enzyme of EruBGC13 with multiple PKS domains (Fig 2). It has annotated hits in different ascomycetes (Fig. S5E). The sixth (EruBGC23) and seventh (EruBGC24) T1pks clusters are located on the scaffold00032 (KK088442.1) with sizes 47.5kb (14 genes) and 48kb (21 genes), respectively (Table 3). EruBGC23 has homologs in Colwellia psychrerythraea, Cyanothece sp. and several strains of Streptomyces (Fig. S4F), while EruBGC24 has similar clusters in Mycobacterium malmoense, Scytonema sp., Chitinophaga sp. and several strains of Streptomyces (Fig. S4G), plus it has also matched with asperfuranone in MIBiG database (Fig. S4G). The core proteins of these two clusters are EYE91651.1 and EYE91696.1, which are annotated as hypothetical protein and putative polyketide synthase, respectively. However, upon scanning annotated homologs, we found that these proteins are T1PKS (Figs. S5F-G), which is also supported by their protein domain organization (Fig 2). The eighth T1pks cluster (EruBGC35) is localized on scaffold00077 in a region of $19.3 \mathrm{~kb}$ and it possesses total 8 genes (Table 3). This BGC is homologous cluster in Saccharothrix espanaensis, Amycolatopsis keratiniphila and Amycolatopsis keratiniphila (Fig. S4H). The core PKS enzyme of EruBGC35 is thiolase-like protein (EYE89967.1), which is 385 residues with tryptophan dimethylallyltransferase (Trp_DMAT, PF11991) domain and it has 75-77\% sequence identities with homologs from other ascomycetes (Fig. S5H).

\subsection{Summary of terpene BGCs from E. rubrum}

We identified ten terpene-based BGCs in E. rubrum genome (table 4). The first terpene BGC EruBGC1 is localized on the scaffold00002 (KK088412.1) with 2 genes in a total size of $11.8 \mathrm{~kb}$ region (Fig. S5 and table 5) and it has no homologous BGC in any known microbial genome (Fig. S4A). The core protein of EruBGC1 is terpenoid synthase (EYE98762.1), 362 residues with trichodiene synthase (TRI5, PFAM ID - PF06330) domain (Fig. 3). This protein shares sequence identities of 50\% to 57\% with homologs in related ascomycetes (Fig. S5). The second terpene producing EruBGC6 is of 21.1 $\mathrm{kb}$ region on the scaffold00003 (KK088413.1) with 9 genes. It has single homologous BGC matching in the genome of Lentzea jiangxiensis (Fig. S4A). There are two terpenoid synthases as EYE98616.1 and EYE98617.1 as core proteins of EruBGC6 with size 337 and 335 residues long with TRI5 (PF06330) and polyprenyl synthetic (PF00348) domain, respectively. EYE98616.1 shares $>70 \%-80 \%$ sequence identities with orthologs in other ascomycetes (Fig. S6), whereas EYE98617.1 has $>53 \%-<75 \%$ sequence identities with orthologs in other ascomycetes (Fig. S7).

The third terpene BGC, EruBGC16 is localized on the scaffold00008 (KK088420.1) in a region of 22.3 $\mathrm{kb}$ from 1,52,089 bp-1,74,460 bp. EruBGC16 shares homologous BGCs from several strains of Gordonia (Fig. 4C). respectively. EruBGC16 is 100\% identical to clavaric acid (Fig. 4C) producing BGC (MIBiG accession ID - BGC0001248) from Hypholoma sublateritium. This indicates that this cluster is capable of producing clavaric acid (molecular formula $-\mathrm{C}_{36} \mathrm{H}_{58} \mathrm{O}_{8}, \mathbf{F i g} 3$ ). The core protein of EruBGC16 is a lanosterol synthase (EYE95851.1) and it possesses two squalene-hopene cyclase protein domains (Fig identities $98 \%$ each and $88 \%$ for lanosterol synthase (Fig. S8) from A. cristatus (ODM19928.1), A. lentulus (GAQ08994.1) and A. udagawae (GAO84757.1), respectively. 


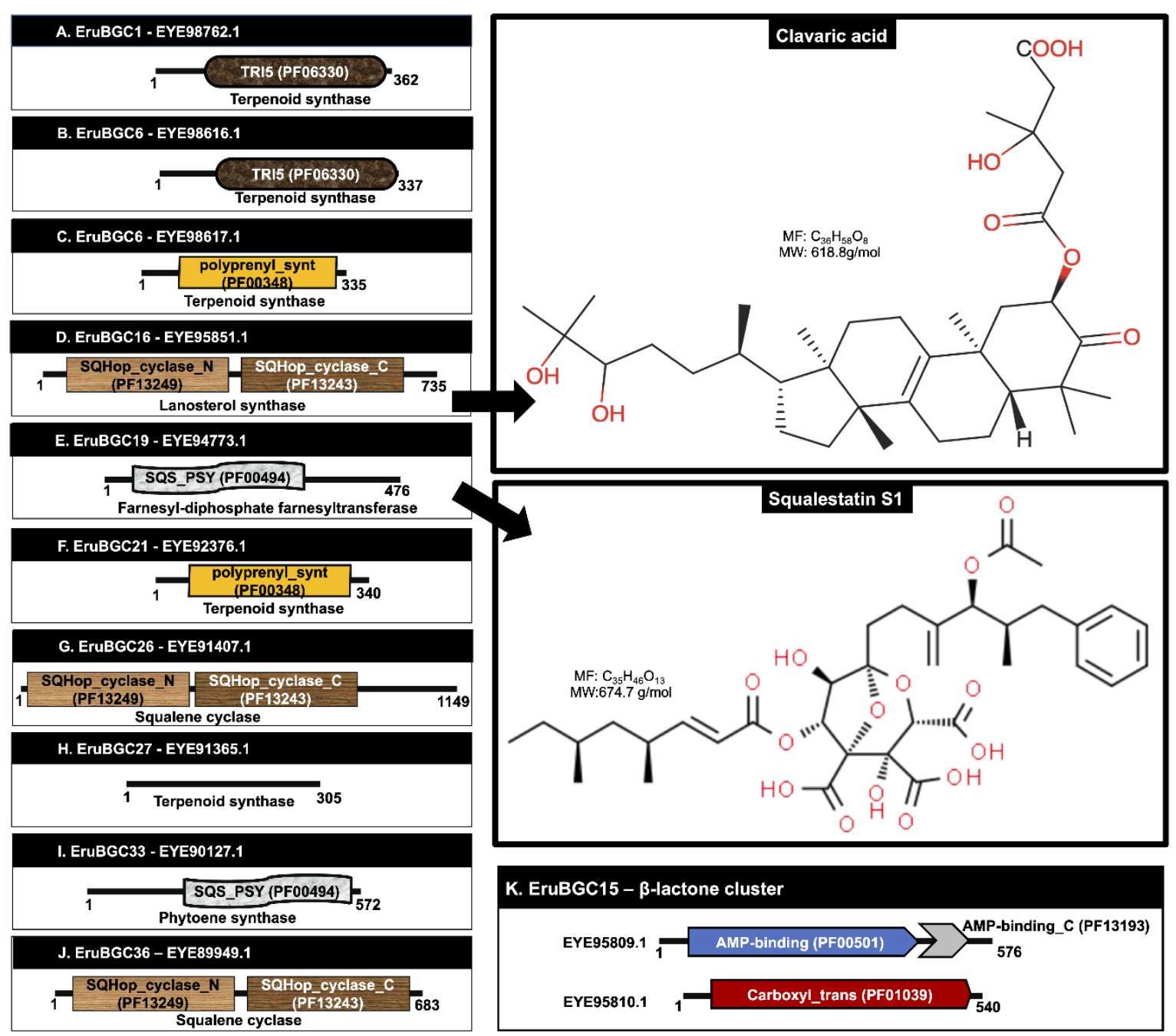

Fig 3. Summary of domain architecture of terpene BGCs of the marine E. rubrum genome.

The 21.6 kb-long fourth BGC terpene BGC, EruBGC19 is mapped on to scaffold00014 (KK088424.1) with 12 genes in total. It shares homologous BGC from Lysinibacillus massiliensis and several Teredinibacter strains (Fig S4D). This cluster is producing squalestatin S1 (Fig 3) with 60\% identities with squalestatin S1 producing BGC from Aspergillus sp. Z5 (BGC0001839, Fig S4D). This illustrates that EruBGC19 is a potent producer of squalestatin $\mathrm{S} 1\left(\mathrm{C}_{35} \mathrm{H}_{46} \mathrm{O}_{13}\right.$, Fig 3). The core enzyme of this cluster is farnesyl-diphosphate farnesyltransferase (EYE94773.1), which is 476 residues and harbors a SQS-PSY (PF00494) domain (Fig 3E). EYE94773.1 shares >80-<95\%, with top homologs (Fig. S9).

The fifth terpene BGC, EruBGC21 is mapped to scaffold00027 (KK088437.1) from 1,86,829 bp to 2,07,933 bp with total size of $21.1 \mathrm{~kb}$ region, possessing 10 genes. It has no homologous BGCs in other species when scanned in public databases (Fig S4E). The core protein of this cluster is terpenoid synthase (EYE92376.1), 340 amino acids long with polyprenyl synthetic (PF00348) domain (Fig 3F). This protein has $85 \%$ sequence identities with orthologs in Aspergillus strains (Fig. S10).

The sixth terpene cluster, EruBGC26 possesses seven genes in the $24.3 \mathrm{~kb}$ region in the scaffold00035 (KK088445.1). EruBGC26 has homologous BGC in Beijerinckia indica subsp. indica ATCC 9039 and several strains of Nitrosomonas and Methylocapsa (Fig S4F). The core enzyme of this BGC is 1149 residues long squalene cyclase (EYE91407.1), with two squalene-hopene cyclase protein domains (Fig 3G) as SQHop_cyclase_N (PF13249) and SQHop_cyclase_C (PF13243) and these domains are capable 
of producing prenyltransferases. Sequence analysis reveals that squalene cyclase (EYE91407.1) has 55-57\% sequence identities with orthologs from different Aspergillus species (Fig. S11).

The seventh terpene cluster (EruBGC27) is 15kb long with 6 genes, which is harbored on the scaffold00036 (KK088446.1). This cluster is novel as we did not find any similar cluster in public databases (Fig S4G). The core backbone of EruBGC27 is terpenoid synthase (EYE91365.1), which is 305 residues long without any protein domain (Fig $3 \mathbf{H})$. This protein has $62-65 \%$ sequence identities with orthologs from different Aspergillus species (Fig. S11). The eighth terpene BGC (EruBGC33) is located on the scaffold00060 (KK088470.1) harboring 7 genes in a 19.7kb fragment and this cluster has homologs in Pseudomonas sp., Rhizobium sp., Massilia sp., and Sandaracinus amylolyticus (Fig S4H). The core protein of EruBGC33 is a phytoene synthase (EYE90127.1) possessing squalene/phytoene synthase (SQS_PSY, PF00494) towards the C-terminal end (Fig 3H). EYE90127.1 has homologs in different Aspergillus strains with sequence identities of $64-67 \%$ (Fig. S12). The ninth terpene cluster, EruBGC36 is mapped to scaffold00079 (KK088489.1) with 9 genes in a region $16.5 \mathrm{~kb}$, but it has three homologous BGCs in different bacterial genomes as Granulicella pectinivorans, Streptomyces ochraceiscleroticus and Delta proteobacterium (Fig S4I). The core protein of this cluster is a squalene cyclase (EYE89949.1), harboring two squalene-hopene cyclase protein domains (Fig 3G) namely SQHop_cyclase_N (PF13249) and SQHop_cyclase_C (PF13243). This protein has sequence identities of $64-67 \%$ with homologs from different Aspergillus strains (Fig. S13). The $10^{\text {th }}$ terpene-based EruBGC15 is $\beta$-lactone cluster on the scaffold00008 (KK088420.1) with 10 genes spanning a size of $24.5 \mathrm{~kb}$. This BGC has homologous clusters in Thauera sp. K11 (NZ_CP023439_c5), several strains Mycobacterium and Bacillus subtilis (Fig S4J). This cluster produces two core proteins as acetyl-CoA synthetase-like protein (EYE95809.1) and aldolase (EYE95810.1) with harboring protein domains as AMP-binding (PF00501) and AMP-binding_C (PF13193), and Carboxyl_trans (PF01039), respectively (Fig 4K). Acetyl-CoA synthetase-like protein (EYE95809.1) depicts 68-79\% identities with close homologs from two Penicillium species and A. udagawae (Fig S14), whereas aldolase (EYE95810.1) shows $>68-73 \%$ sequence identities with selected ascomycetes (Fig S15).

\subsection{There are four hybrid BGCs in marine Eurotium genome}

The first hybrid BGC is EruBGC7, which is mapped to scaffold00003 (KK088413.1). This fragment has a size of $44.2 \mathrm{~kb}$ with 17 genes (Table 5) and it has counterparts in several strains of Bacillus, plus Amycolatopsis keratiniphila, Actinoplanes awajinensis and Allokutzneria albata (Fig S16A). EruBGC7 is producing a product of hybrid of NRPS and indole with help of three major proteins as aromatic prenyl-transferase (EYE98742.1), acetyl-CoA synthetase-like protein (EYE98744.1) and putative dimethylallyl tryptophan synthase (EYE98746.1, Fig 1). The second hybrid BGC is EruBGC17 as a hybrid of T1PKS and indole genes localized on scaffold00012 (KK088422.1) in a $93.3 \mathrm{~kb}$ region with 36 genes (Fig S16A). EruBGC17 has homologous BGCs in several strains of Streptomyces plus Mycobacterium, Kitasatospora, and Frankia (Fig S16B). There are three main core proteins of this cluster as ketoacyl-synt-domain-containing protein (EYE95320.1), polyketide synthase (EYE95336.1, Fig 2) and aromatic prenyltransferase (EYE95342.1). This cluster is capable of producing epipyriculol $\left(\mathrm{C}_{14} \mathrm{H}_{16} \mathrm{O}_{4}\right.$, Fig $\left.2 \mathrm{~F}\right)$ with phytotoxic properties. The third hybrid BGC (EruBGC28) is a 50.3kb region (with 19 genes) on the scaffold00036 (KK088447.1). EruBGC28 has orthologous clusters in several strains of Mycobacterium and Methylobacter (Fig S16C). This BGC is encoding a hybrid product based on T1PKS as 6-methylsalicylic acid synthase MsaS (EYE91246.1, Fig 2) and NRPS-like as ochratoxin A non-ribosomal peptide synthetase (EYE91247.1, Fig 1). The end product of this cluster is 
asperlactone $\left(\mathrm{C}_{9} \mathrm{H}_{12} \mathrm{O}_{4}\right.$, Fig 2G) with nematocidal, insecticidal, antibacterial, and antifungal properties. The fourth hybrid cluster (EruBGC30) is mapped on the scaffold00043 (KK088453.1) a $\sim 67 \mathrm{~kb}$ region with 22 genes. This cluster has homologous BGCs in several bacterial genomes with the top three being Streptomyces violens, Actinosynnema sp., and Mycobacterium sp. (Fig S16D). This cluster is a hybrid of T1PKS (EYE90804.1, Fig 2) and NRPS (EYE90819.1 - acetyl-CoA synthetase-like protein, Fig 1).

\subsection{Overview of siderophore BGCs from E. rubrum}

We have detected two BGCs in Eurotium genome, which are capable of producing siderophores namely EruBGC9 and EruBGC12 (Table 6). EruBGC9 is the siderophore producing BGC on the scaffold00005 (Genbank ID KK088415.1) from 110,568 bp to 122,685 bp in 11.9 kb region. This cluster has no homologous clusters in public databases. However, the siderophore producing protein (GenBank Id - EYE97444.1) is largely somewhat hypothetical as homology detection using BLASTP resulted in $64 \%$ and $62 \%$ sequence identities with aerobactin siderophore biosynthesis, IucA/IucC from Penicillium roqueforti FM164 (GenBank ID - OOO13908.1) and taurine catabolism dioxygenase TauD/TfdA from Aspergillus oryzae (GenBank ID - OOO13908.1), respectively (Fig. 4A).
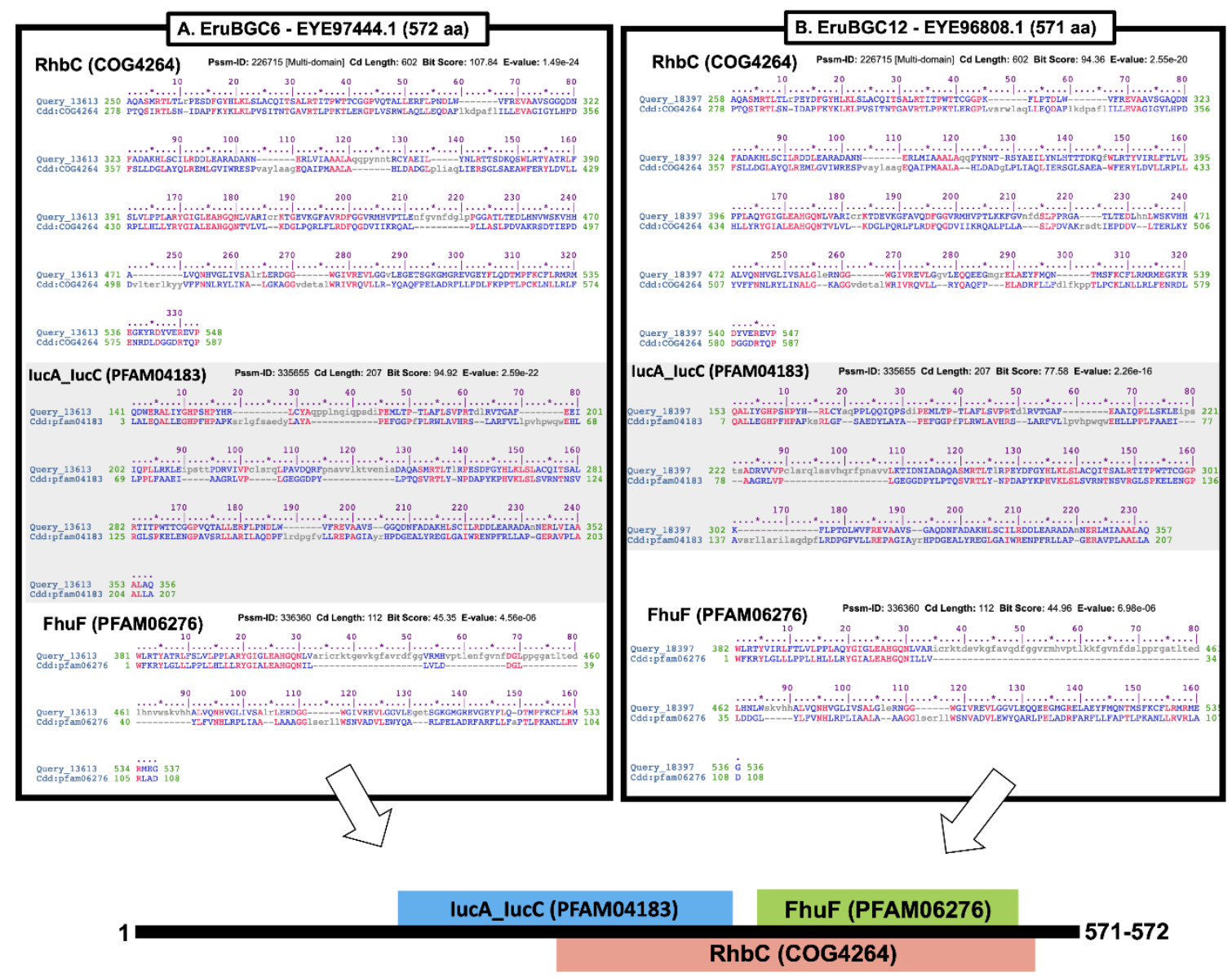

Fig 4. Overview of siderophore producing proteins and their domains encoded by biosynthetic gene clusters EruBGC6 and EruBGC12. 
It also shows $65.24 \%, 65.23 \%$ and $64.22 \%$ sequence identities with IucC family-domain-containing proteins from A. tamarii (KAE8167994.1), A. pseudotamarii (KAE8143495.1) and A. caelatus (XP_031924195.1), respectively (Fig. 4B). The second siderophore BGC, EruBGC12 is mapped to scaffold00007 (KK088417.1) from 372,420-384,556 bp with total size of $12.1 \mathrm{~kb}$. It has no similarities with any known BGCs in the known databases. The core protein of this cluster is EYE96808.1 which is has similar protein domains as of EYE97444.1 (from EruBGC6). These two proteins have similar size with three domains required for siderophore biosynthesis (Fig. 4), namely siderophore synthetase component, RhbC (COG4264), IucA_IucC (Pfam ID - PFAM04183) and ferric iron reductase FhuF (Pfam ID - PFAM06276). This suggests that these two proteins have capabilities for producing siderophore.

Advancement in genomics technologies has helped us in setting up multi-omics mining affords to explore the SM producing capability of marine fungi and understanding their genomic location, regulatory mechanisms and conditions in these SM compounds can be activated [11]. We have utilized multi-omics methods for characterization of marine fungi with focus on deciphering their capabilities of producing SM like Calcarisporium sp. KF525 and Pestalotiopsis sp. KF079 and Scopulariopsis $[5,6]$. These studies hinted that marine fungi are the excellent sources of bio-active compounds [5-8] with antibacterial and anti-cancerous properties like scopularide A and B [5]. All in all, this study unravelled 36 BGCs from marine E. rubrum. It clearily supports the same idea that marine fungi are rich source of the future drugs [12-16]. Omics approaches have widely open genetics and biotechnological applications focusing the marine species as examplified by biotechnological applications as textile dyes of two laccase-encoding genes from for marine Pestalotiopsis sp. KF079 [17]. In similar fashion, this study opens up the opportunities for future explorations of marine E. rubrum and BGCs for potential roles as future drugs. 


\section{Materials and Methods}

\subsection{Collection of genome and protein sequences from halophilic marine fungus Erutium rubrum}

We downloaded the genomic and protein sequence data of the halophilic marine fungus E. rubrum from GenBank using assembly accession - GCA_000600275.1.

\subsection{Identification of putative secondary metabolite producing proteins}

Initially, we screened putative secondary metabolites encoding proteins using BLASTP [18] with an E-value < $1 \mathrm{e}^{-10}$ after setting up the local BLAST database.

\subsection{Identification of biosysnthetic gene clusters (BGCs)}

We analysed E. rubrum genome for putative BGC clusters by antiSMASH5 [19], using the standard parameters with options of bacterial and fungal BGC scanning set ups.

\subsection{Identification of biosysnthetic gene clusters (BGCs)}

We identified the functional domains of PKSs and NRPSs as previously described [20], using a combinations of tools namely antiSMASH5 [19], NCBI Conserved Domain Database [21], InterPro [22] and the PKS/NRPS Analysis Web-site [23]. We performed several rounds of specialized BLAST [18] for scanning homologs of genes and /or corresponding proteins at an E-value $<1 \mathrm{e}^{-10}$. We identified Pfam domains using HMMER [24].

\subsection{Re-annotation of core proteins of BGCs}

Annotation of proteins of interests using BLAST [18] and scanned annotated BLAST hits with minimum coverage of $70 \%$ of query and minimum sequence identity of $50 \%$.

\subsection{Protein sequence and phylogenetics analyses}

We carried out protein sequence analysis of core proteins using COBALT [25]. We performed phylogenetic analyses of core proteins using annotated proteins using Distance tree method. We visualised the resulted phylogenetic trees using Blast Tree View.

Author Contributions: Conceptualization, Abhishek Kumar; Data curation, Obul Reddy Bandapali, Alisha Parveen, Pradeep Phule, Jens Laurids Sørensen and Abhishek Kumar; Formal analysis, Obul Reddy Bandapali, Frederik Teilfeldt Hansen, Alisha Parveen, Pradeep Phule, Emmagouni Sharath Kumar Goud, Suraj Kumar Acharya, Jens Laurids Sørensen and Abhishek Kumar; Investigation, Obul Reddy Bandapali, Frederik Teilfeldt Hansen, Emmagouni Sharath Kumar Goud, Suraj Kumar Acharya and Abhishek Kumar; Methodology, Obul Reddy Bandapali, Frederik Teilfeldt Hansen, Alisha Parveen, Pradeep Phule and Abhishek Kumar; Project administration, Abhishek Kumar; Resources, Jens Laurids Sørensen and Abhishek Kumar; Supervision, Jens Laurids Sørensen and Abhishek Kumar; Validation, Abhishek Kumar; Visualization, Abhishek Kumar; Writing - original draft, Abhishek Kumar; Writing - review \& editing, Obul Reddy Bandapali, Frederik Teilfeldt Hansen, Alisha Parveen, Pradeep Phule, Jens Laurids Sørensen and Abhishek Kumar.

Funding: This research received no external funding. 
Conflicts of Interest: The authors declare no conflict of interest.

Acknowledgements: A.K. is a recipient of Ramalingaswami Re-Retry Faculty Fellowship (Grant; BT/RLF/Reentry/38/2017) from Department of Biotechnology (DBT), Government of India (GOI). E.S.K.G. and S.K.A. are thankful to DBT, GOI and Council of Scientific and Industrial Research (CSIR), GOI for their fellowships, respectively.

\section{Appendix A}

Appendix A carries all supplementary data.

\section{References}

1. Oren, A.; Gunde-Cimerman, N., Fungal life in the dead sea. Prog Mol Subcell Biol 2012, 53, 115-32.

2. Buchalo, A. S.; Nevo, E.; Wasser, S. P.; Oren, A.; Molitoris, H. P., Fungal life in the extremely hypersaline water of the Dead Sea: first records. Proc Biol Sci 1998, 265, (1404), 1461-5.

3. Ionescu, D.; Siebert, C.; Polerecky, L.; Munwes, Y. Y.; Lott, C.; Hausler, S.; Bizic-Ionescu, M.; Quast, C.; Peplies, J.; Glockner, F. O.; Ramette, A.; Rodiger, T.; Dittmar, T.; Oren, A.; Geyer, S.; Stark, H. J.; Sauter, M.; Licha, T.; Laronne, J. B.; de Beer, D., Microbial and chemical characterization of underwater fresh water springs in the Dead Sea. PLoS One 2012, 7, (6), e38319.

4. Kis-Papo, T.; Weig, A. R.; Riley, R.; Persoh, D.; Salamov, A.; Sun, H.; Lipzen, A.; Wasser, S. P.; Rambold, G.; Grigoriev, I. V.; Nevo, E., Genomic adaptations of the halophilic Dead Sea filamentous fungus Eurotium rubrum. Nat Commun 2014, 5, 3745.

5. Kumar, A.; Henrissat, B.; Arvas, M.; Syed, M. F.; Thieme, N.; Benz, J. P.; Sorensen, J. L.; Record, E.; Poggeler, S.; Kempken, F., De Novo Assembly and Genome Analyses of the Marine-Derived Scopulariopsis brevicaulis Strain LF580 Unravels Life-Style Traits and Anticancerous Scopularide Biosynthetic Gene Cluster. PLoS One 2015, 10, (10), e0140398.

6. Kumar, A.; Sorensen, J. L.; Hansen, F. T.; Arvas, M.; Syed, M. F.; Hassan, L.; Benz, J. P.; Record, E.; Henrissat, B.; Poggeler, S.; Kempken, F., Genome Sequencing and analyses of Two Marine Fungi from the North Sea Unraveled a Plethora of Novel Biosynthetic Gene Clusters. Sci Rep 2018, 8, (1), 10187.

7. Redou, V.; Kumar, A.; Hainaut, M.; Henrissat, B.; Record, E.; Barbier, G.; Burgaud, G., Draft Genome Sequence of the Deep-Sea Ascomycetous Filamentous Fungus Cadophora malorum Mo12 from the Mid-Atlantic Ridge Reveals Its Biotechnological Potential. Genome Announc 2016, 4, (4).

8. Redou, V.; Kumar, A.; Hainaut, M.; Henrissat, B.; Record, E.; Barbier, G.; Burgaud, G., Draft Genome Sequence of the Deep-Sea Basidiomycetous Yeast Cryptococcus sp. Strain Mo29 Reveals Its Biotechnological Potential. Genome Announc 2016, 4, (4).

9. Gupta, R. N.; Spenser, I. D., Biosynthesis of the piperidine nucleus. The mode of incorporation of lysine into pipecolic acid and into piperidine alkaloids. J Biol Chem 1969, 244, (1), 88-94.

10. Watson, A. A.; Fleet, G. W.; Asano, N.; Molyneux, R. J.; Nash, R. J., Polyhydroxylated alkaloids -- natural occurrence and therapeutic applications. Phytochemistry 2001, 56, (3), 265-95.

11. Brakhage, A. A., Regulation of fungal secondary metabolism. Nature reviews. Microbiology 2013, 11, (1), 21-32.

12. Konig, G. M.; Kehraus, S.; Seibert, S. F.; Abdel-Lateff, A.; Muller, D., Natural products from marine organisms and their associated microbes. Chembiochem 2006, 7, (2), 229-38.

13. Ebada, S. S.; Proksch, P., Bioactive secondary metabolites from marine-derived fungi. In Marine Pharmacognosy:Trends and Applications, Kim, S. K., Ed. CRC Press Taylor \& Francis Group, LLC, Boca Raton: 2013; pp 27-51. 
14. Saleem, M.; Ali, M. S.; Hussain, S.; Jabbar, A.; Ashraf, M.; Lee, Y. S., Marine natural products of fungal origin. Nat Prod Rep 2007, 24, (5), 1142-52.

15. Bugni, T. S.; Ireland, C. M., Marine-derived fungi: a chemically and biologically diverse group of microorganisms. Nat Prod Rep 2004, 21, (1), 143-63.

16. Rateb, M. E.; Ebel, R., Secondary metabolites of fungi from marine habitats. Nat Prod Rep 2011, 28, (2), 290-344.

17. Wikee, S.; Hatton, J.; Turbe-Doan, A.; Mathieu, Y.; Daou, M.; Lomascolo, A.; Kumar, A.; Lumyong, S.; Sciara, G.; Faulds, C. B.; Record, E., Characterization and Dye Decolorization Potential of Two Laccases from the Marine-Derived Fungus Pestalotiopsis sp. Int J Mol Sci 2019, 20, (8).

18. Altschul, S. F.; Madden, T. L.; Schaffer, A. A.; Zhang, J.; Zhang, Z.; Miller, W.; Lipman, D. J., Gapped BLAST and PSI-BLAST: a new generation of protein database search programs. Nucleic Acids Res 1997, 25, (17), 3389-402.

19. Blin, K.; Shaw, S.; Steinke, K.; Villebro, R.; Ziemert, N.; Lee, S. Y.; Medema, M. H.; Weber, T., antiSMASH 5.0: updates to the secondary metabolite genome mining pipeline. Nucleic Acids Res 2019, 47, (W1), W81-W87.

20. Hansen, F. T.; Gardiner, D. M.; Lysoe, E.; Fuertes, P. R.; Tudzynski, B.; Wiemann, P.; Sondergaard, T. E.; Giese, H.; Brodersen, D. E.; Sorensen, J. L., An update to polyketide synthase and non-ribosomal synthetase genes and nomenclature in Fusarium. Fungal genetics and biology : FG \& B 2015, 75, 20-9.

21. Marchler-Bauer, A.; Lu, S.; Anderson, J. B.; Chitsaz, F.; Derbyshire, M. K.; DeWeese-Scott, C.; Fong, J. H.; Geer, L. Y.; Geer, R. C.; Gonzales, N. R.; Gwadz, M.; Hurwitz, D. I.; Jackson, J. D.; Ke, Z.; Lanczycki, C. J.; Lu, F.; Marchler, G. H.; Mullokandov, M.; Omelchenko, M. V.; Robertson, C. L.; Song, J. S.; Thanki, N.; Yamashita, R. A.; Zhang, D.; Zhang, N.; Zheng, C.; Bryant, S. H., CDD: a Conserved Domain Database for the functional annotation of proteins. Nucleic acids research 2011, 39, (Database issue), D2259.

22. Hunter, S.; Jones, P.; Mitchell, A.; Apweiler, R.; Attwood, T. K.; Bateman, A.; Bernard, T.; Binns, D.; Bork, P.; Burge, S.; de Castro, E.; Coggill, P.; Corbett, M.; Das, U.; Daugherty, L.; Duquenne, L.; Finn, R. D.; Fraser, M.; Gough, J.; Haft, D.; Hulo, N.; Kahn, D.; Kelly, E.; Letunic, I.; Lonsdale, D.; Lopez, R.; Madera, M.; Maslen, J.; McAnulla, C.; McDowall, J.; McMenamin, C.; Mi, H.; Mutowo-Muellenet, P.; Mulder, N.; Natale, D.; Orengo, C.; Pesseat, S.; Punta, M.; Quinn, A. F.; Rivoire, C.; Sangrador-Vegas, A.; Selengut, J. D.; Sigrist, C. J.; Scheremetjew, M.; Tate, J.; Thimmajanarthanan, M.; Thomas, P. D.; Wu, C. H.; Yeats, C.; Yong, S. Y., InterPro in 2011: new developments in the family and domain prediction database. Nucleic acids research 2012, 40, (Database issue), D306-12.

23. Bachmann, B. O.; Ravel, J., Chapter 8. Methods for in silico prediction of microbial polyketide and nonribosomal peptide biosynthetic pathways from DNA sequence data. Methods Enzymol 2009, 458, 181-217.

24. Eddy, S. R., Accelerated Profile HMM Searches. PLoS Comput Biol 2011, 7, (10), e1002195.

25. Papadopoulos, J. S.; Agarwala, R., COBALT: constraint-based alignment tool for multiple protein sequences. Bioinformatics 2007, 23, (9), 1073-9. 
Table 1. Overview of NRPS-producing BGCs, their genes and proteins.

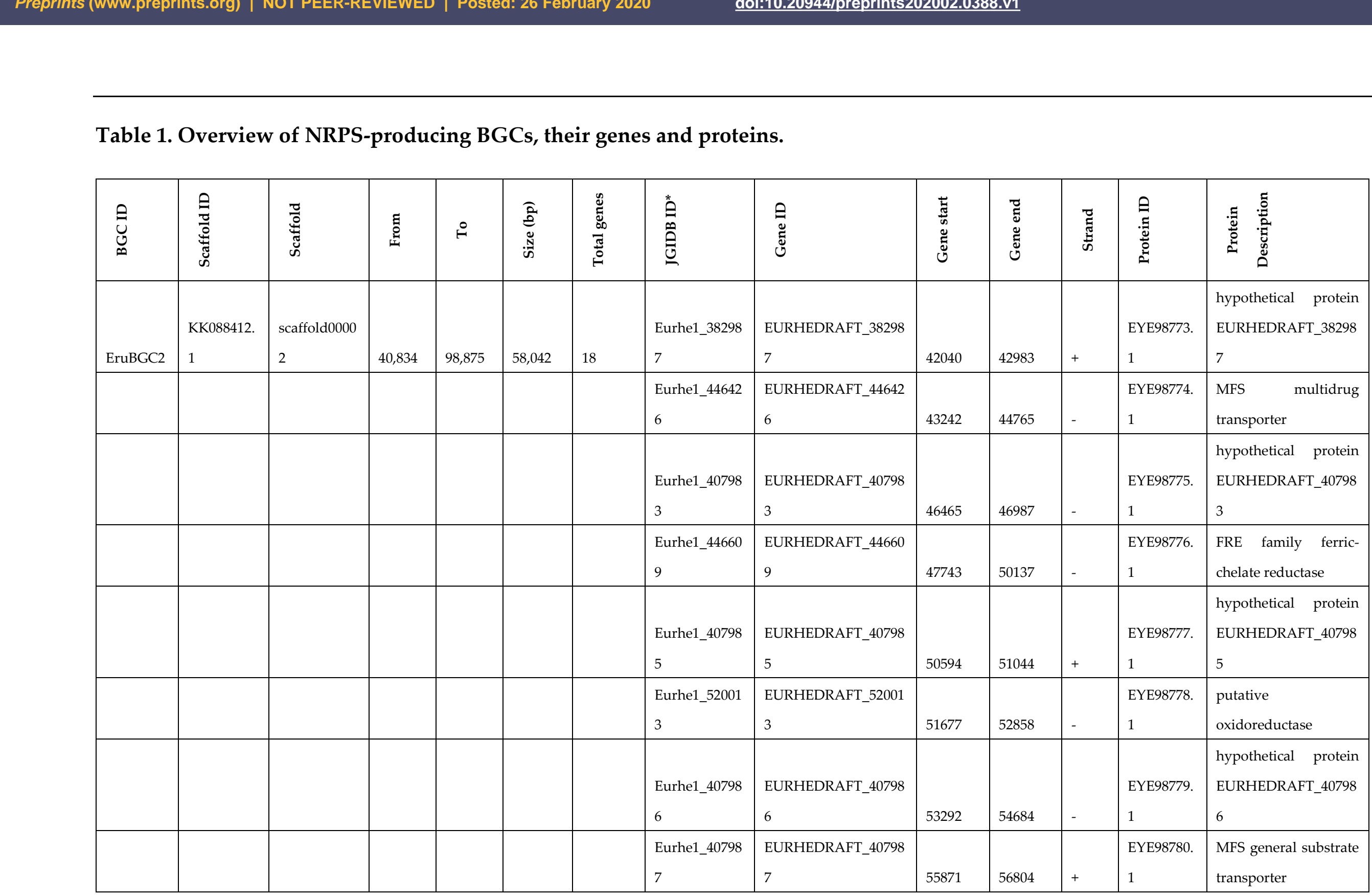




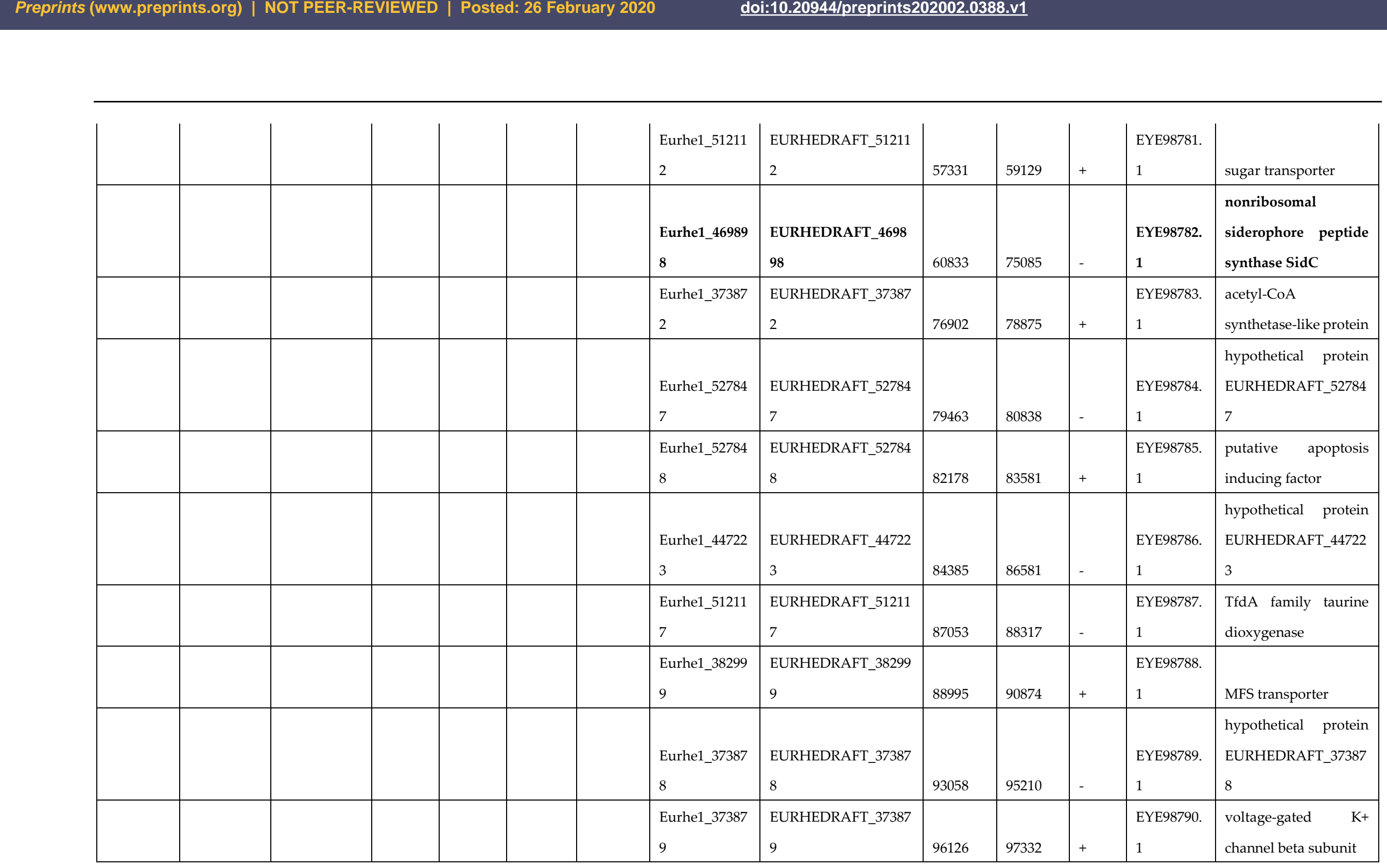




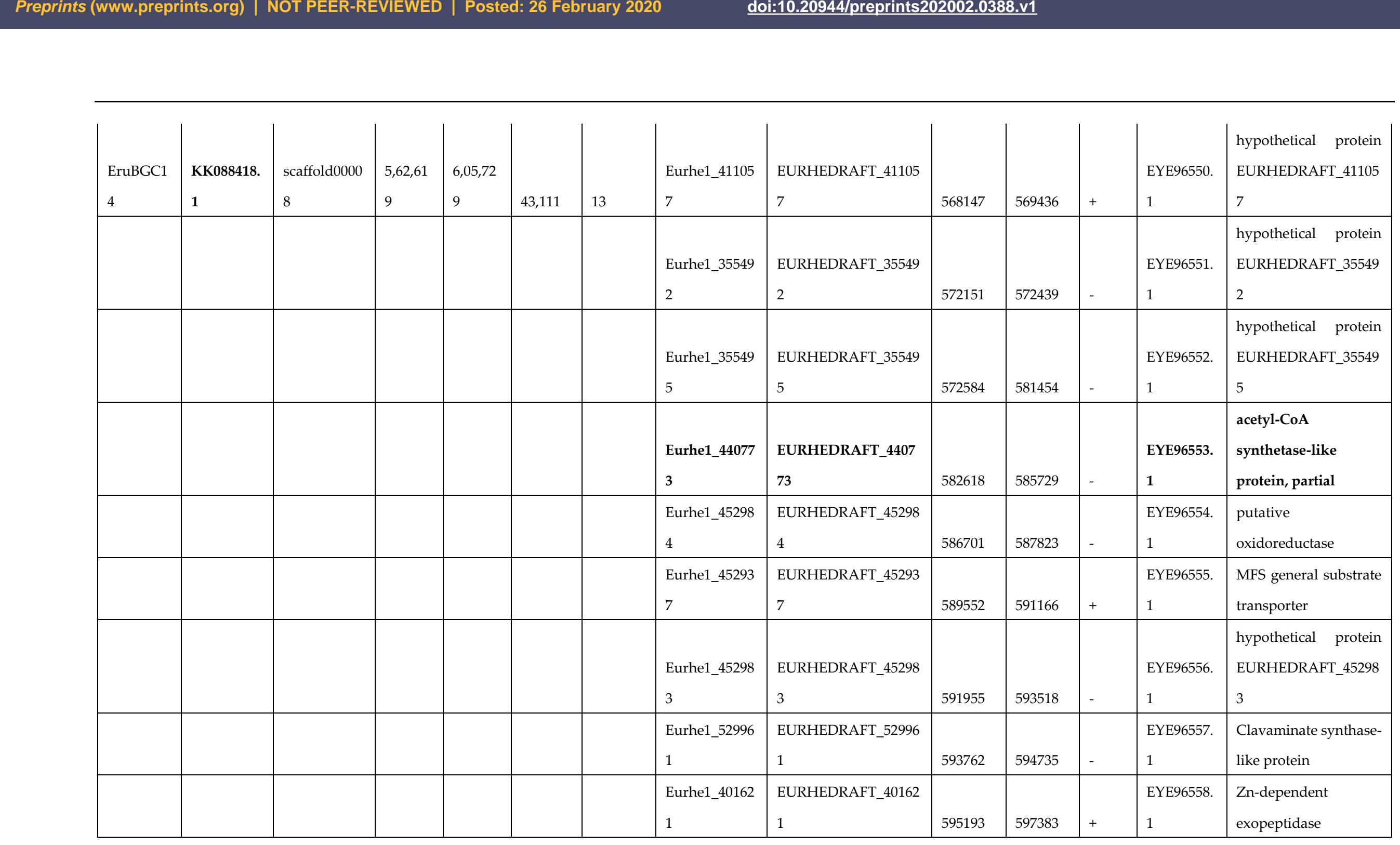




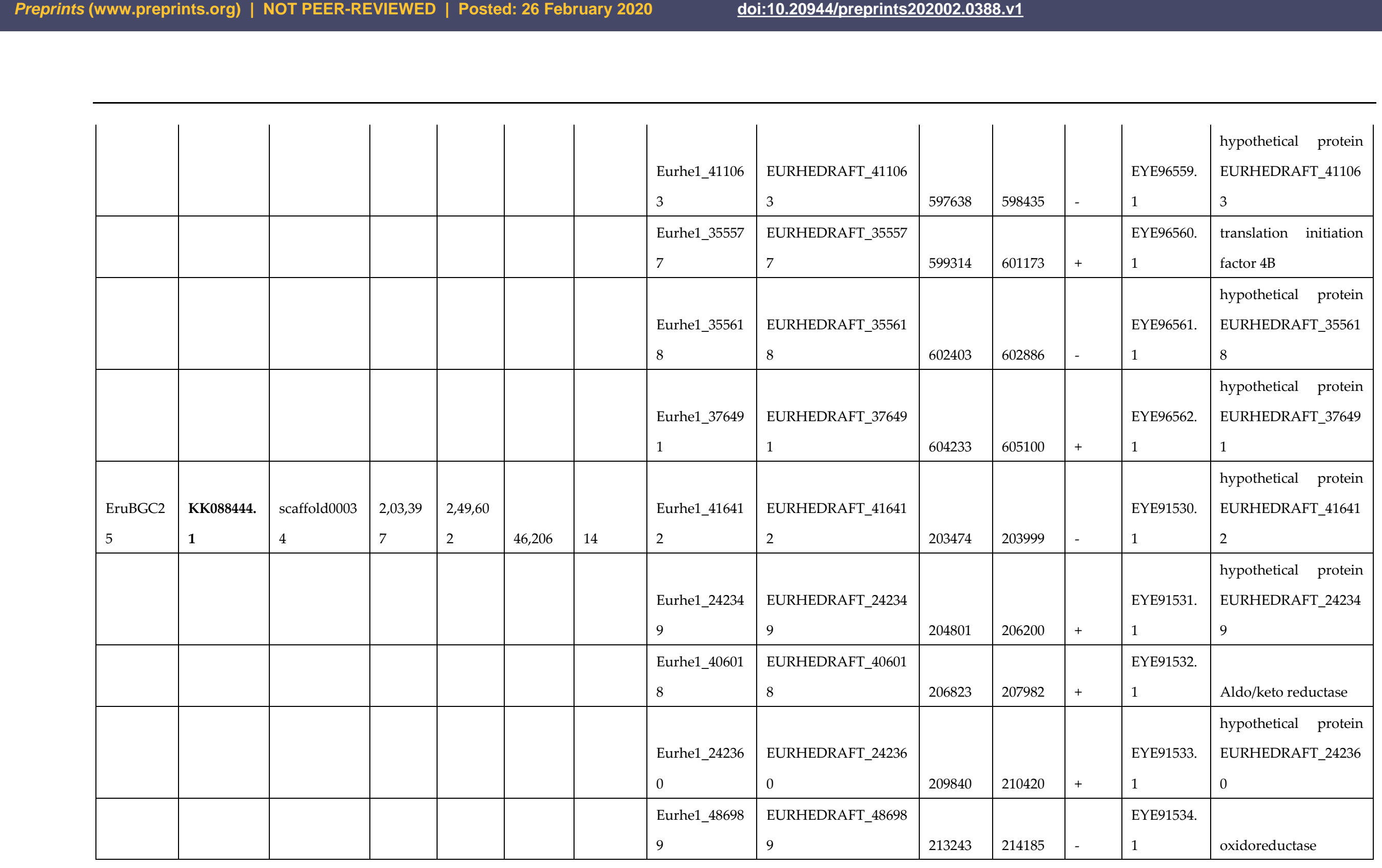




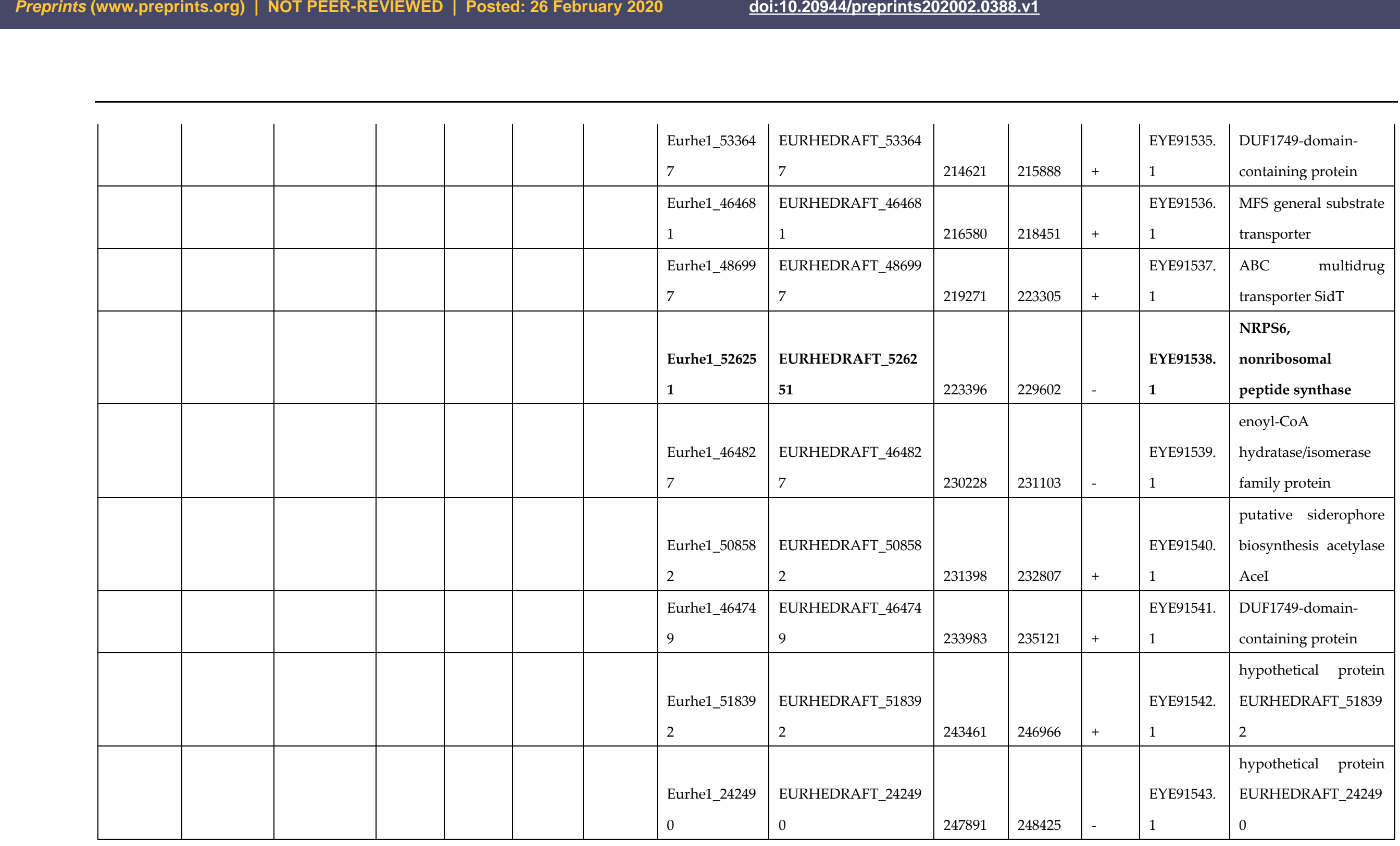




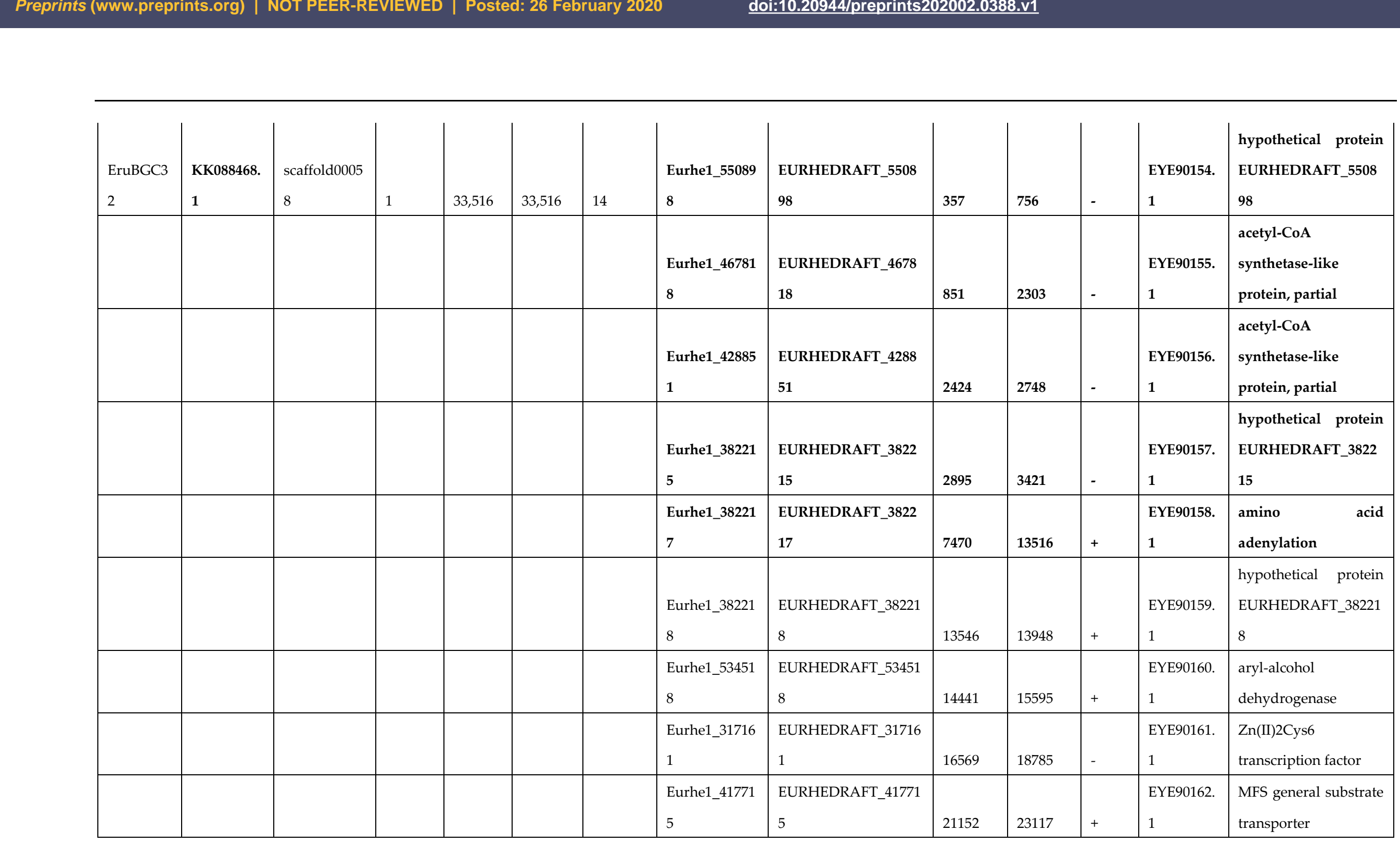




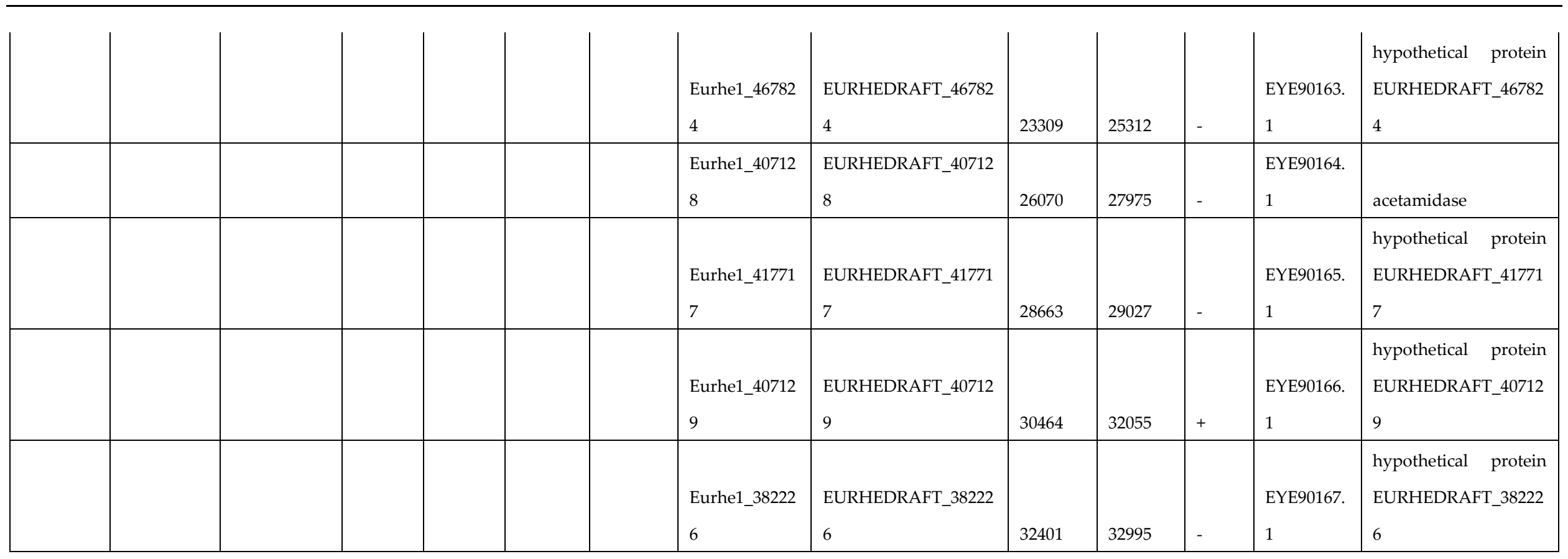

${ }^{*}$ Core gene is marked by Bold letters

Table 2. Summary of NRPS-like BGCs, their genes and proteins.

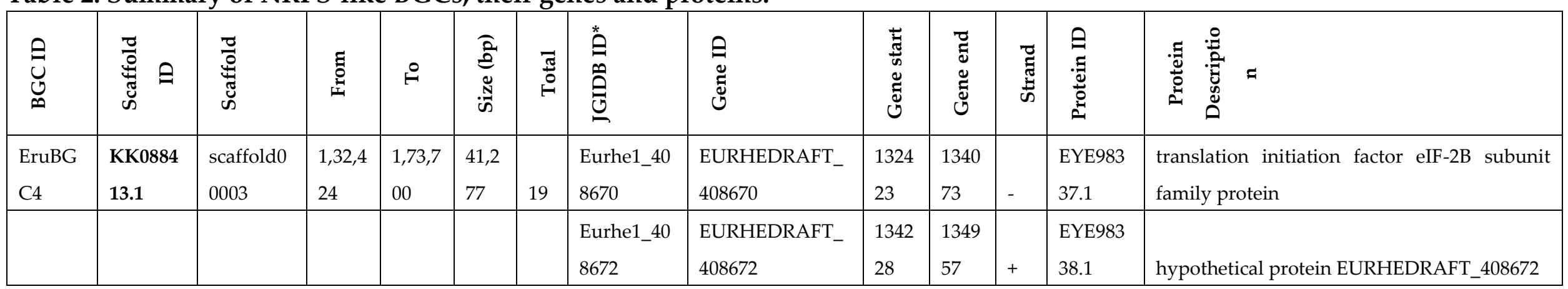




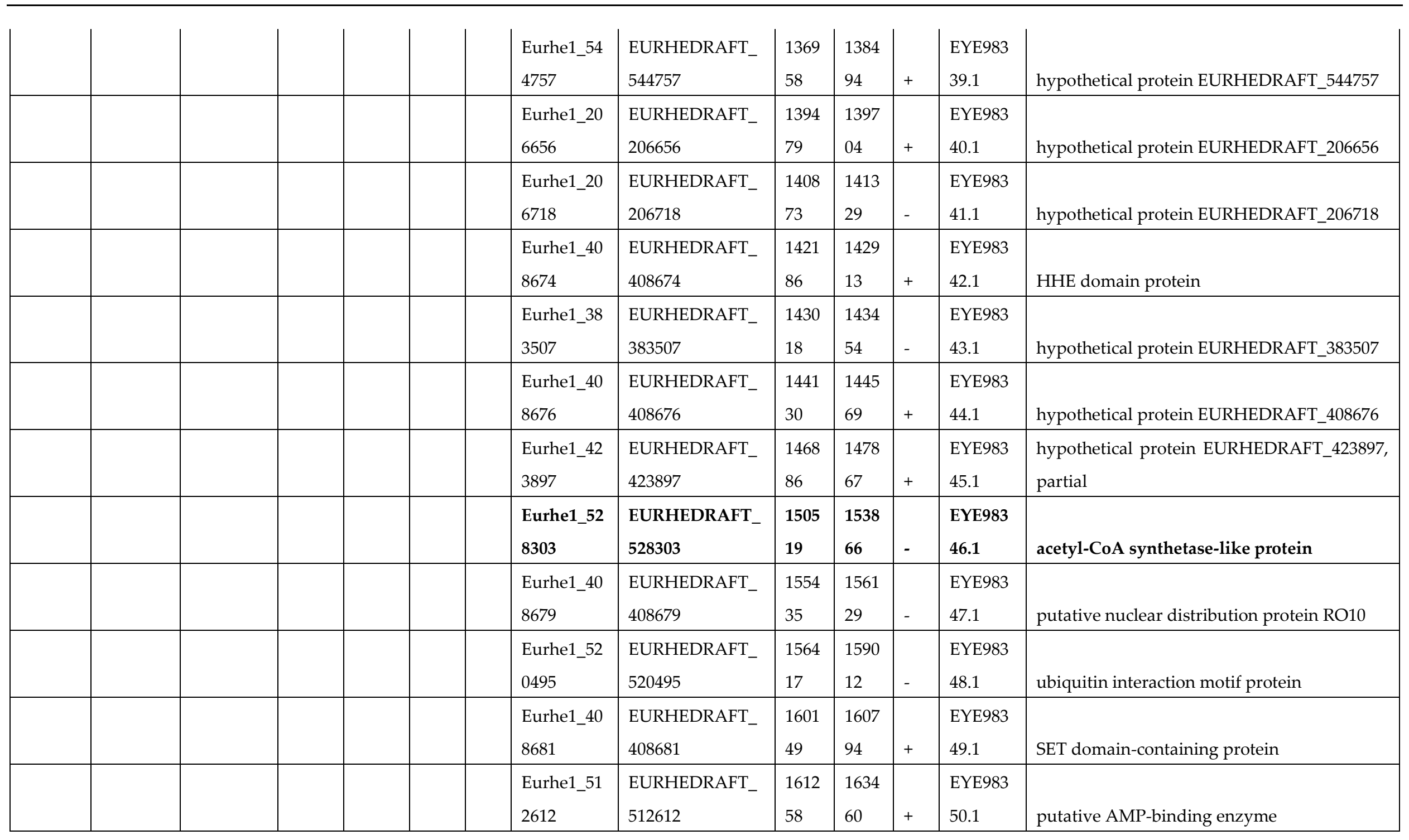




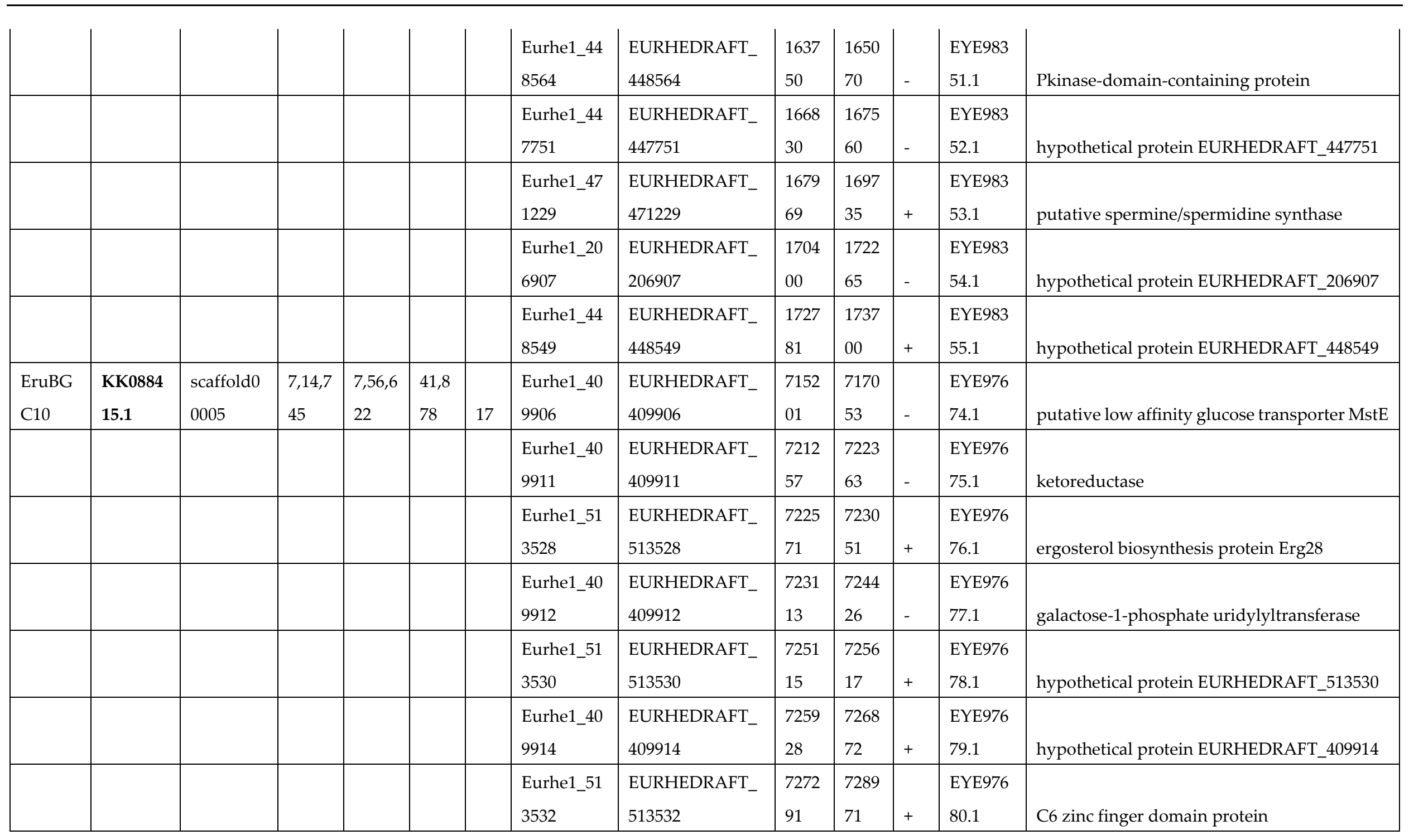




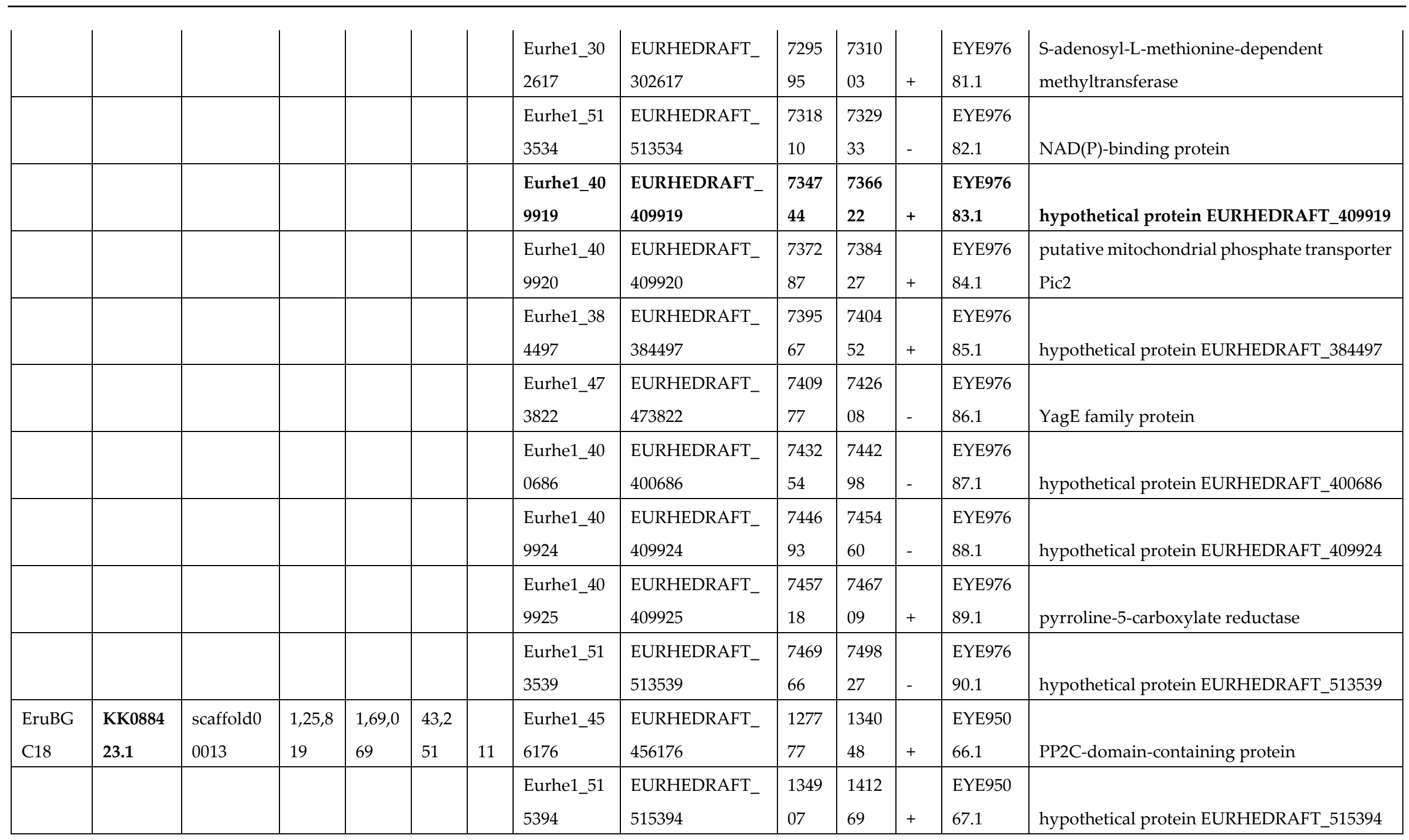




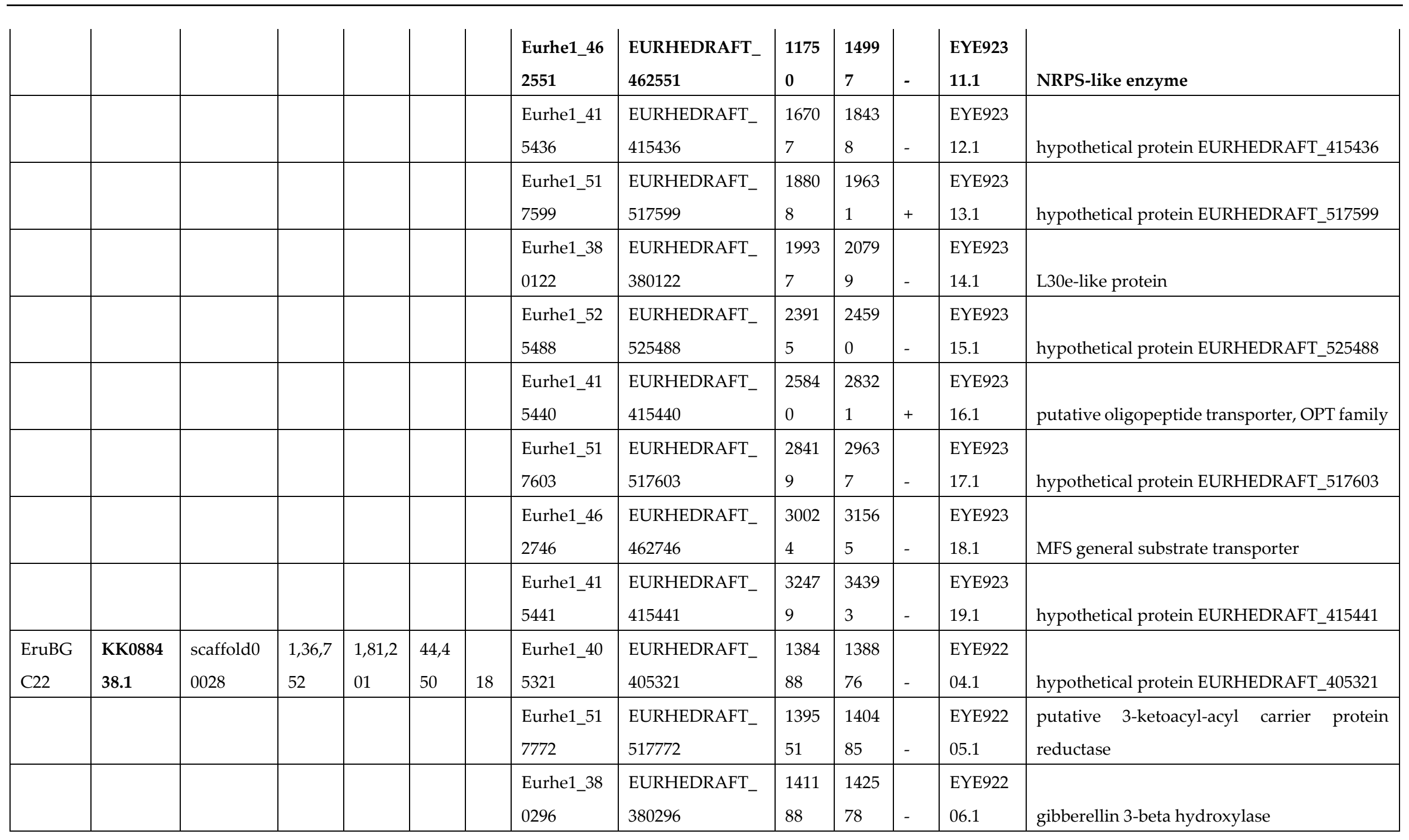




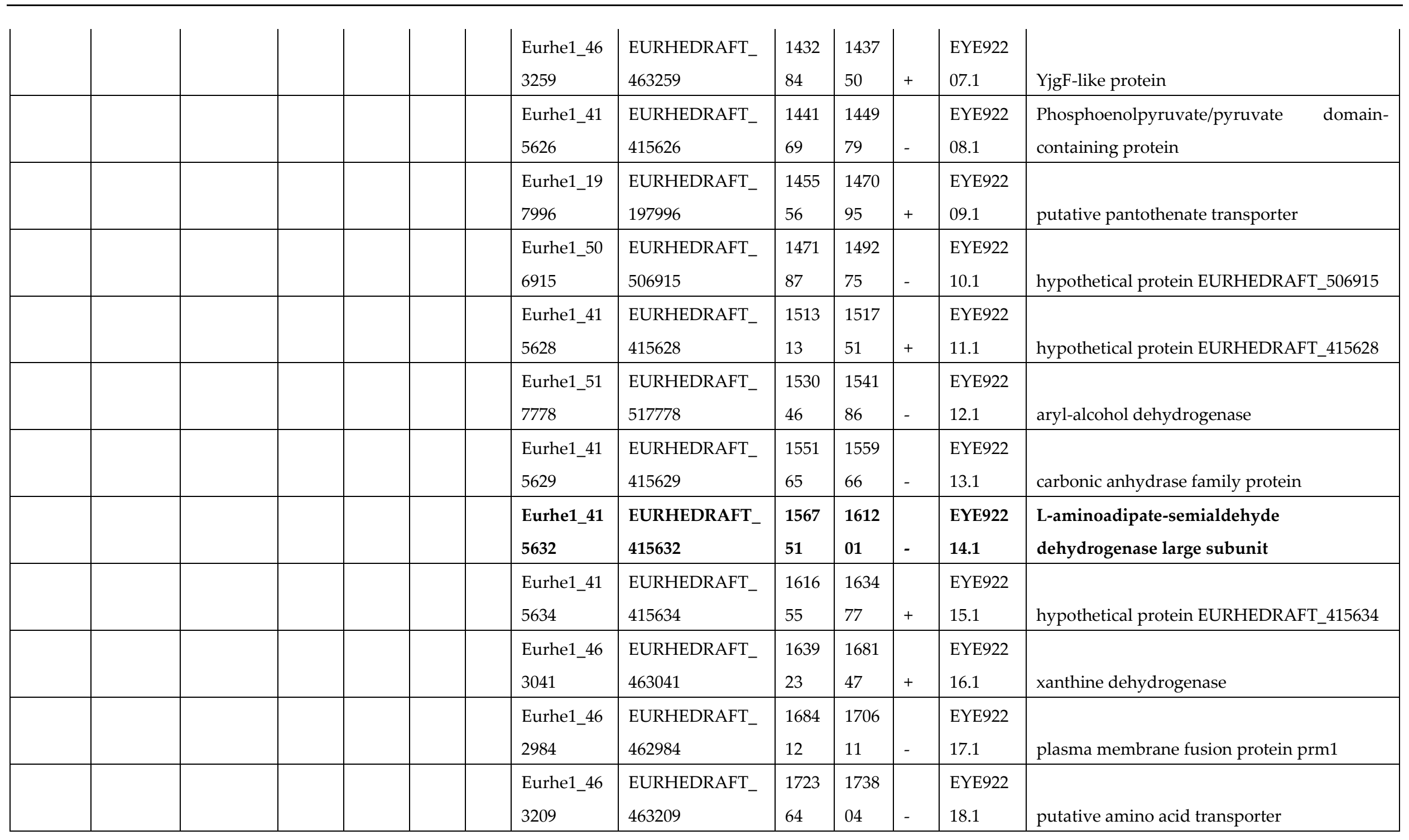




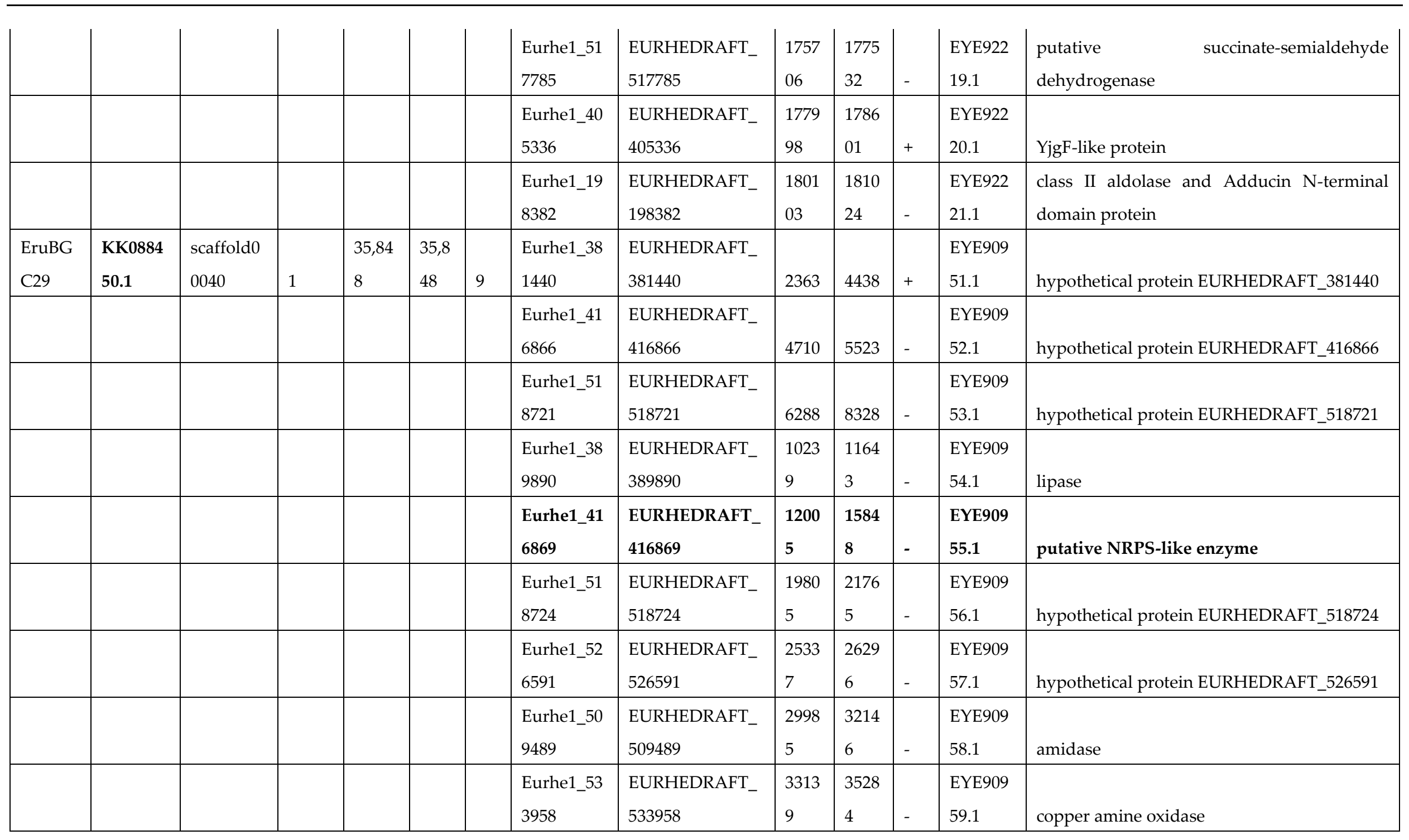




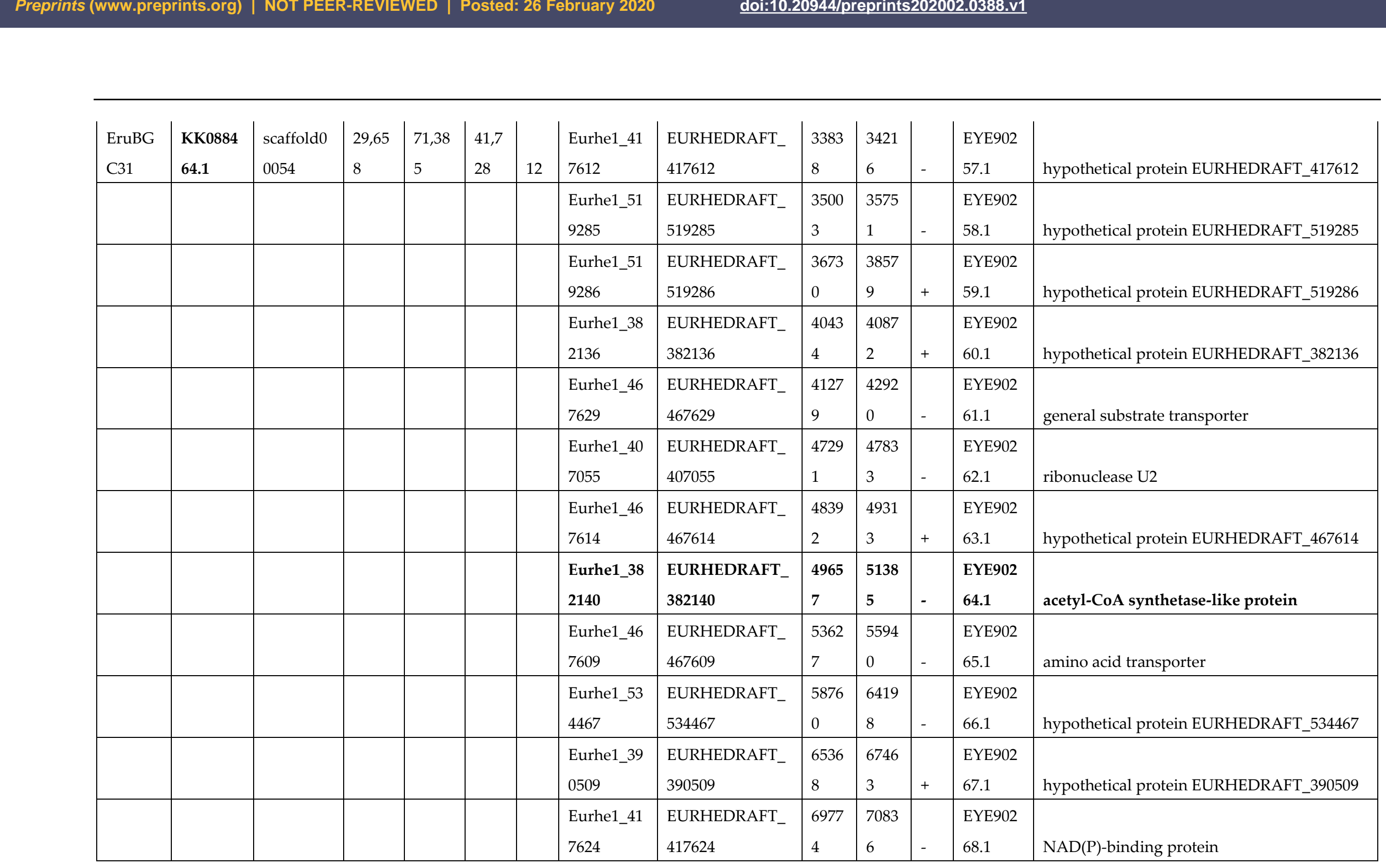




\begin{tabular}{|c|c|c|c|c|c|c|c|c|c|c|c|c|c|}
\hline $\begin{array}{l}\text { EruBG } \\
\text { C34 }\end{array}$ & $\begin{array}{l}\text { KK0884 } \\
74.1\end{array}$ & $\begin{array}{l}\text { scaffold0 } \\
0064\end{array}$ & 607 & $\begin{array}{l}30,88 \\
4\end{array}$ & $\begin{array}{l}30,2 \\
78\end{array}$ & 7 & $\begin{array}{l}\text { Eurhe1_51 } \\
9395\end{array}$ & $\begin{array}{l}\text { EURHEDRAFT_ } \\
519395\end{array}$ & 4441 & 8228 & - & $\begin{array}{l}\text { EYE900 } \\
78.1\end{array}$ & hypothetical protein EURHEDRAFT_519395 \\
\hline & & & & & & & $\begin{array}{l}\text { Eurhe1_55 } \\
2159\end{array}$ & $\begin{array}{l}\text { EURHEDRAFT } \\
552159\end{array}$ & 8804 & 9053 & - & $\begin{array}{l}\text { EYE900 } \\
79.1\end{array}$ & $\begin{array}{l}\text { hypothetical protein EURHEDRAFT_552159, } \\
\text { partial }\end{array}$ \\
\hline & & & & & & & $\begin{array}{l}\text { Eurhe1_46 } \\
8048\end{array}$ & $\begin{array}{l}\text { EURHEDRAFT_ } \\
468048\end{array}$ & 9055 & 9313 & - & $\begin{array}{l}\text { EYE900 } \\
80.1\end{array}$ & $\begin{array}{l}\text { hypothetical protein EURHEDRAFT_468048, } \\
\text { partial }\end{array}$ \\
\hline & & & & & & & $\begin{array}{l}\text { Eurhe1_33 } \\
3683\end{array}$ & $\begin{array}{l}\text { EURHEDRAFT_ } \\
333683\end{array}$ & $\begin{array}{l}1362 \\
6\end{array}$ & $\begin{array}{l}1387 \\
5\end{array}$ & + & $\begin{array}{l}\text { EYE900 } \\
82.1\end{array}$ & hypothetical protein EURHEDRAFT_333683 \\
\hline & & & & & & & $\begin{array}{l}\text { Eurhe1_55 } \\
2178\end{array}$ & $\begin{array}{l}\text { EURHEDRAFT } \\
552178\end{array}$ & $\begin{array}{l}2060 \\
6\end{array}$ & $\begin{array}{l}2603 \\
8\end{array}$ & + & $\begin{array}{l}\text { EYE900 } \\
83.1\end{array}$ & acetyl-CoA synthetase-like protein \\
\hline & & & & & & & $\begin{array}{l}\text { Eurhe1_38 } \\
2301\end{array}$ & $\begin{array}{l}\text { EURHEDRAFT } \\
382301\end{array}$ & $\begin{array}{l}2798 \\
9\end{array}$ & $\begin{array}{l}2913 \\
7\end{array}$ & - & $\begin{array}{l}\text { EYE900 } \\
84.1\end{array}$ & hypothetical protein EURHEDRAFT_382301 \\
\hline
\end{tabular}

${ }^{*}$ Core gene is marked by Bold letters

Table 3. Overview of T1pks-producing BGCs, their genes and proteins.

\begin{tabular}{|c|c|c|c|c|c|c|c|c|c|c|c|c|c|c|c|c|}
\hline $\begin{array}{l}\text { : } \\
\text { D }\end{array}$ & 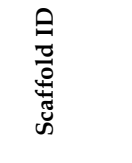 & 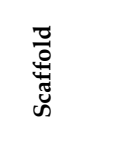 & 总 & $\stackrel{\circ}{\circ}$ & 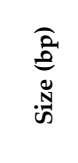 & 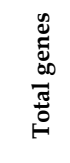 & 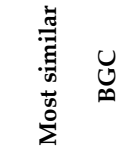 & 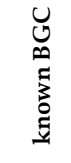 & 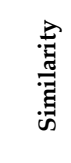 & 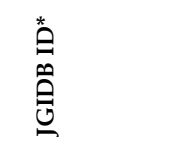 & $\begin{array}{l}\text { O } \\
\text { ভँّ }\end{array}$ & 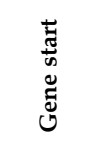 & $\begin{array}{l}\bar{\Xi} \\
\bar{\Xi} \\
\tilde{\Xi} \\
u\end{array}$ & 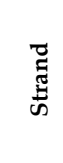 & 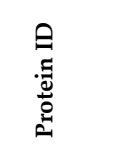 & 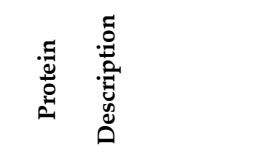 \\
\hline
\end{tabular}




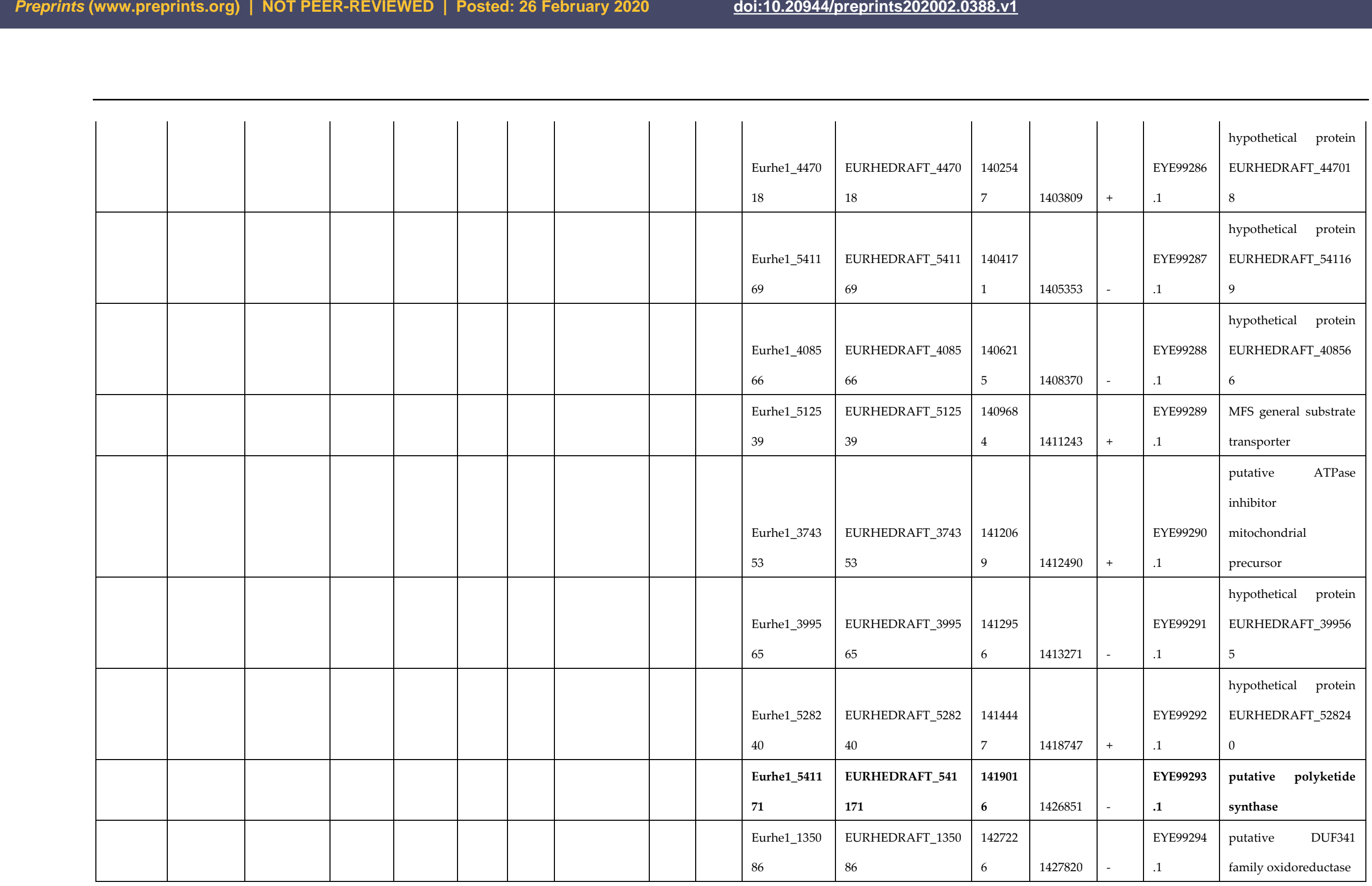




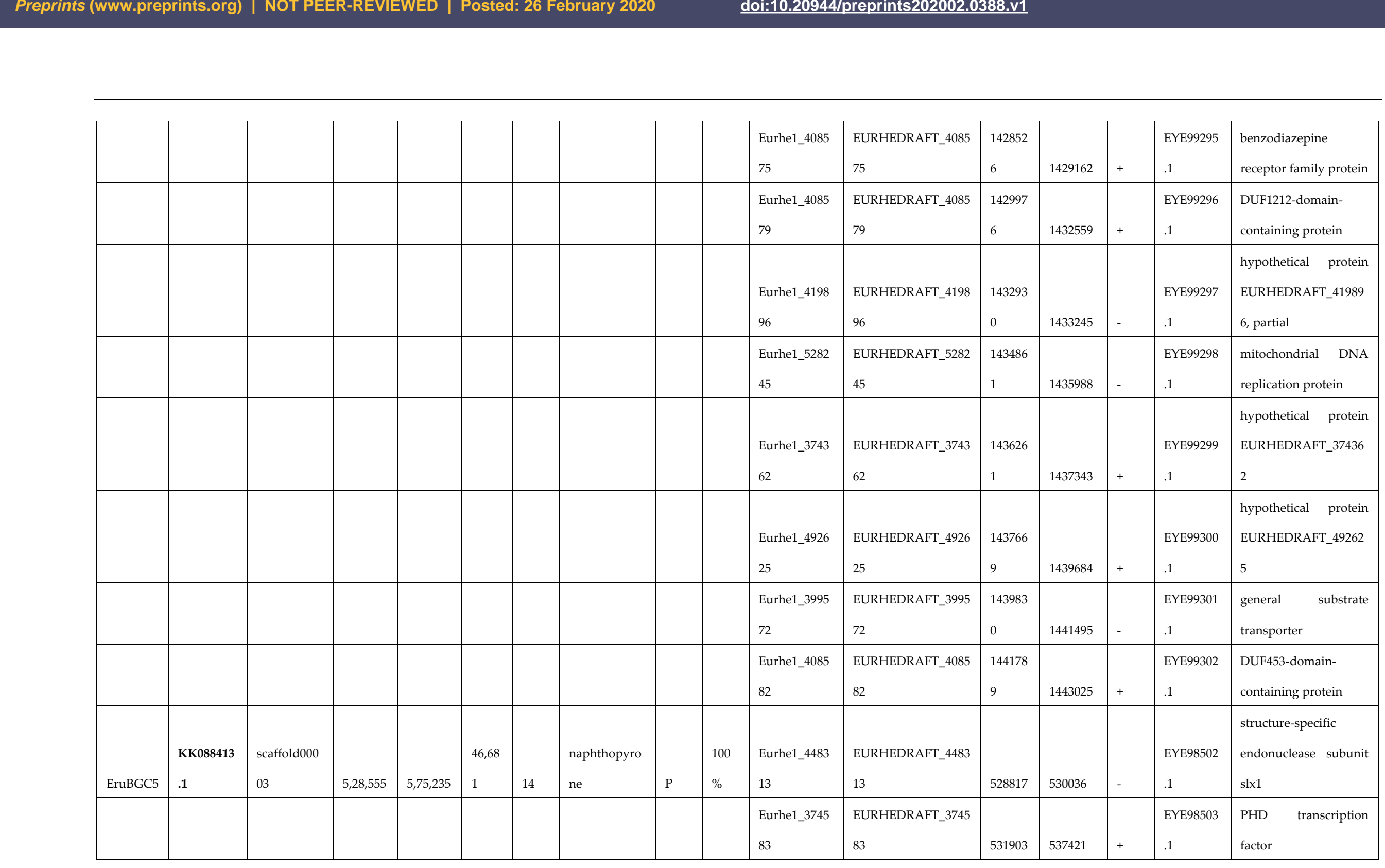




\begin{tabular}{|c|c|c|c|c|c|c|c|c|}
\hline & & & & 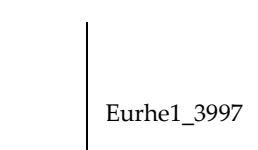 & 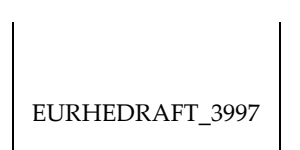 & & $\left.\right|_{\text {mesese }}$ & ratien \\
\hline & & & & 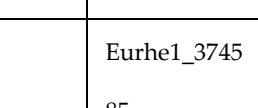 & & \begin{tabular}{|l|l} 
& \\
\end{tabular} & Extresers & \\
\hline & & & & 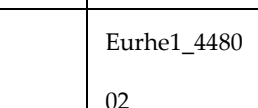 & & 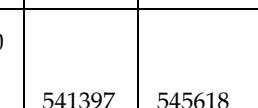 & 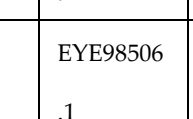 & 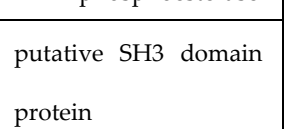 \\
\hline & & & & tatum & & 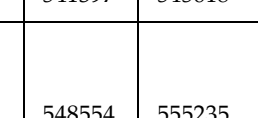 & Eressosor & 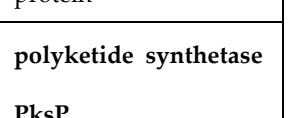 \\
\hline & & & & 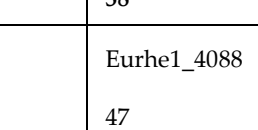 & & 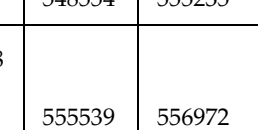 & birseses & \\
\hline & & & & tion & 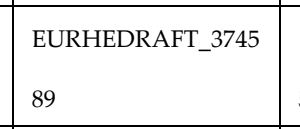 & 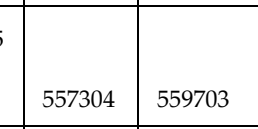 & 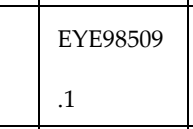 & 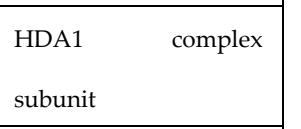 \\
\hline & & & & 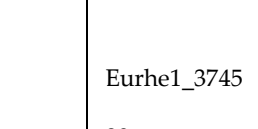 & 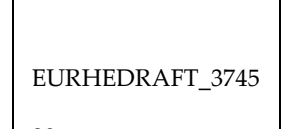 & 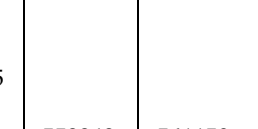 & 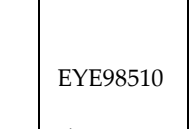 & 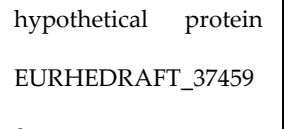 \\
\hline & & & & 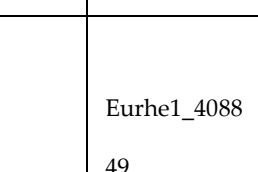 & 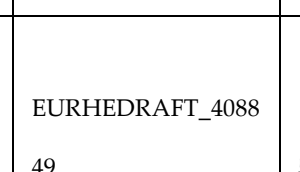 & Soum & Eresest & 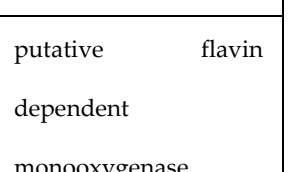 \\
\hline & & & & Erately 356 & & & 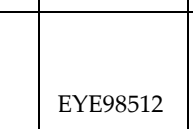 & 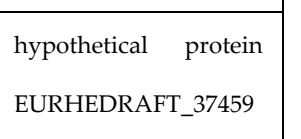 \\
\hline & & & & & & 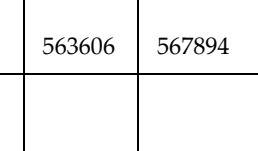 & 1 & $=2$ \\
\hline & & & & 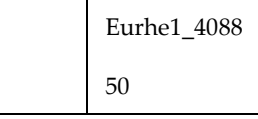 & 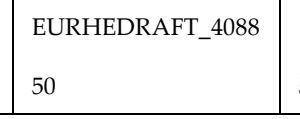 & 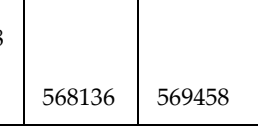 & Exysesis & 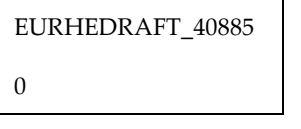 \\
\hline
\end{tabular}




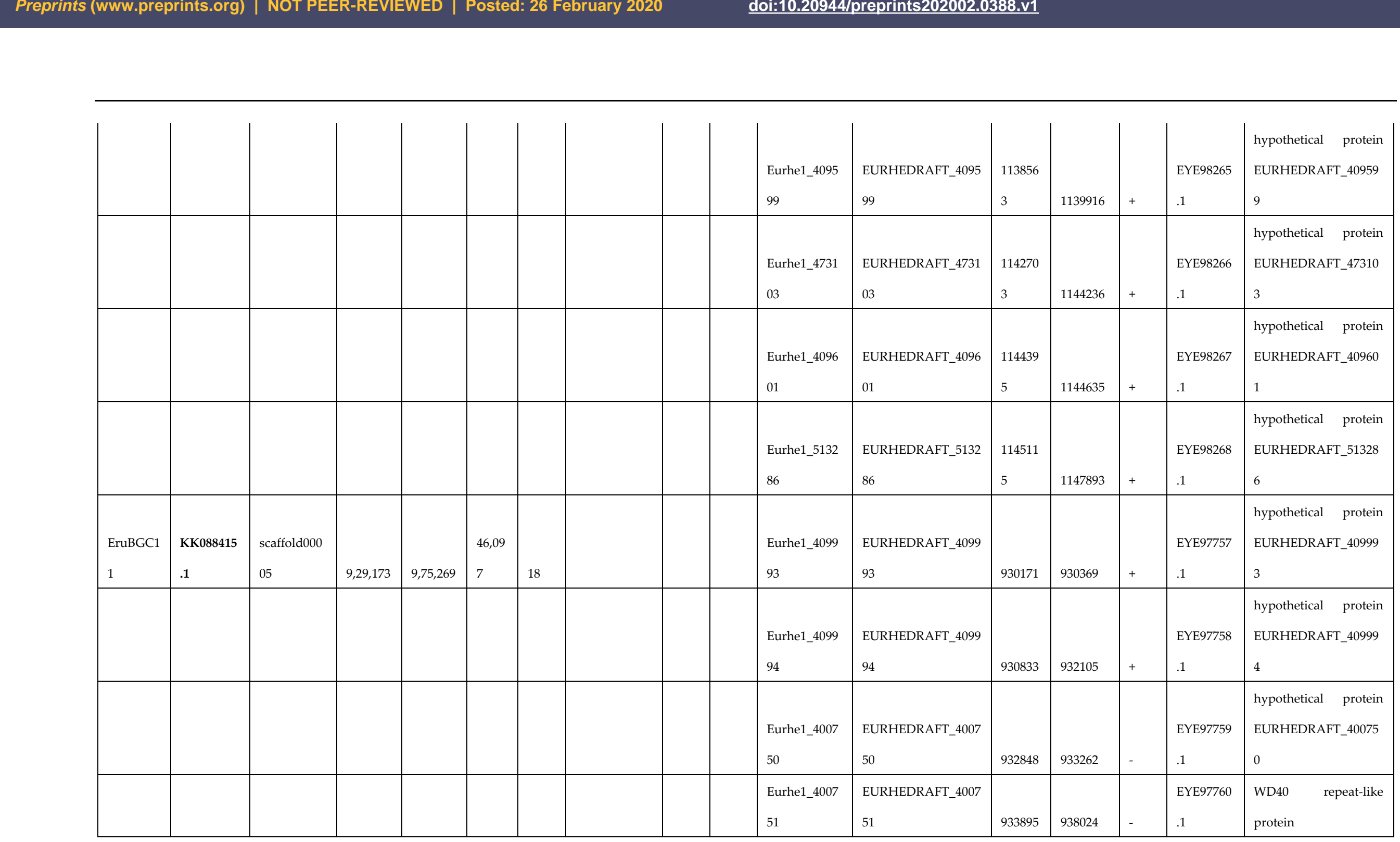




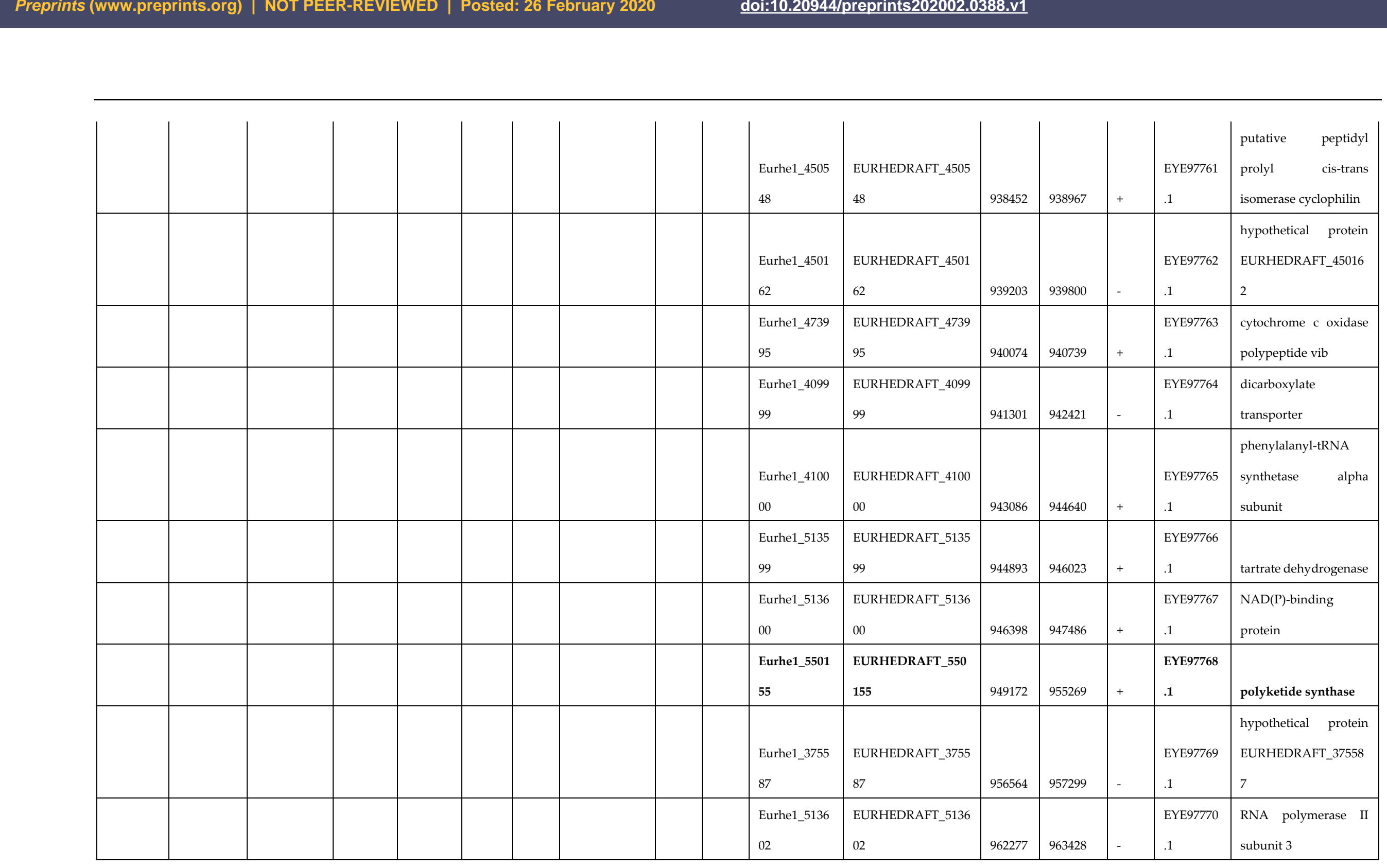




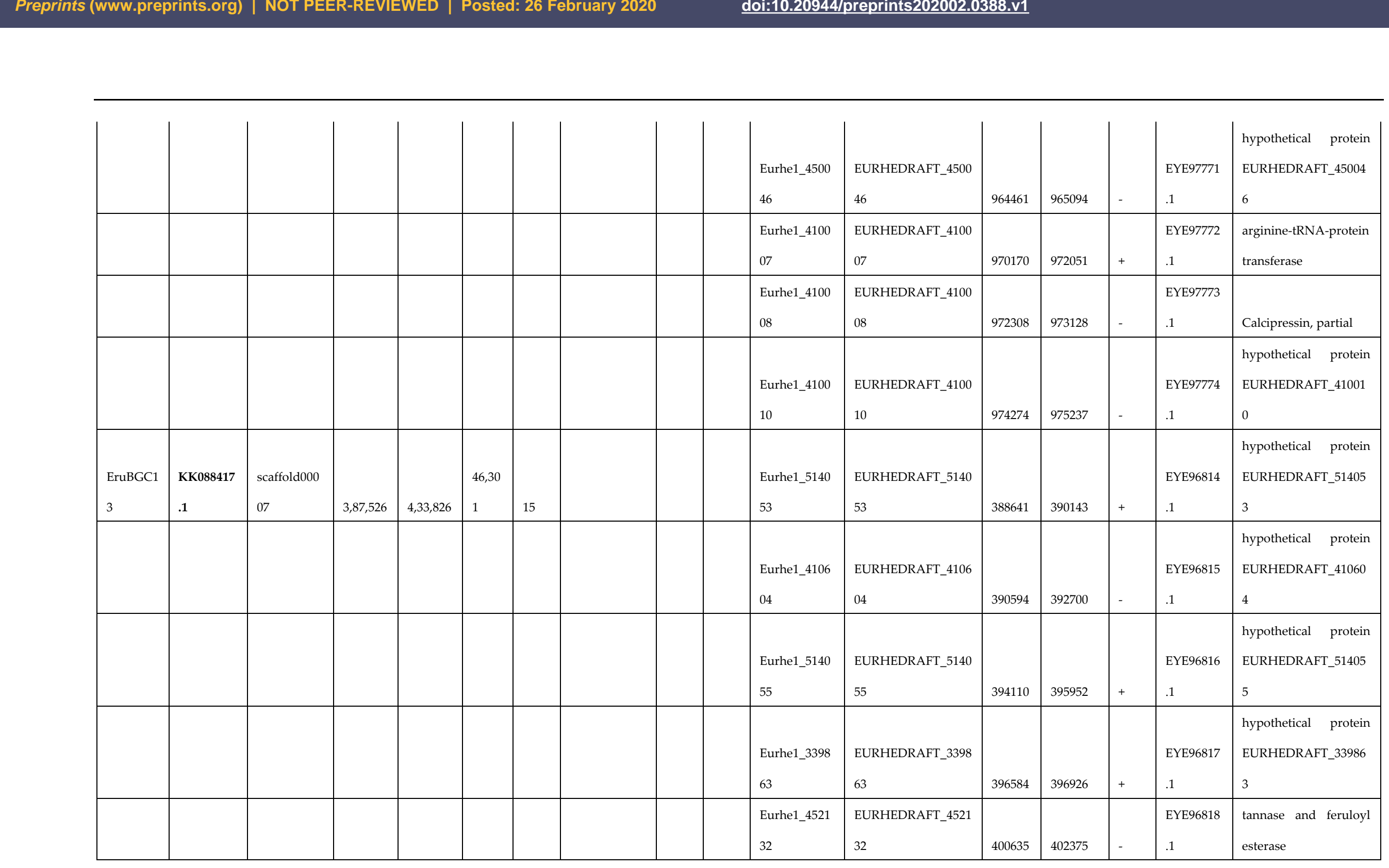




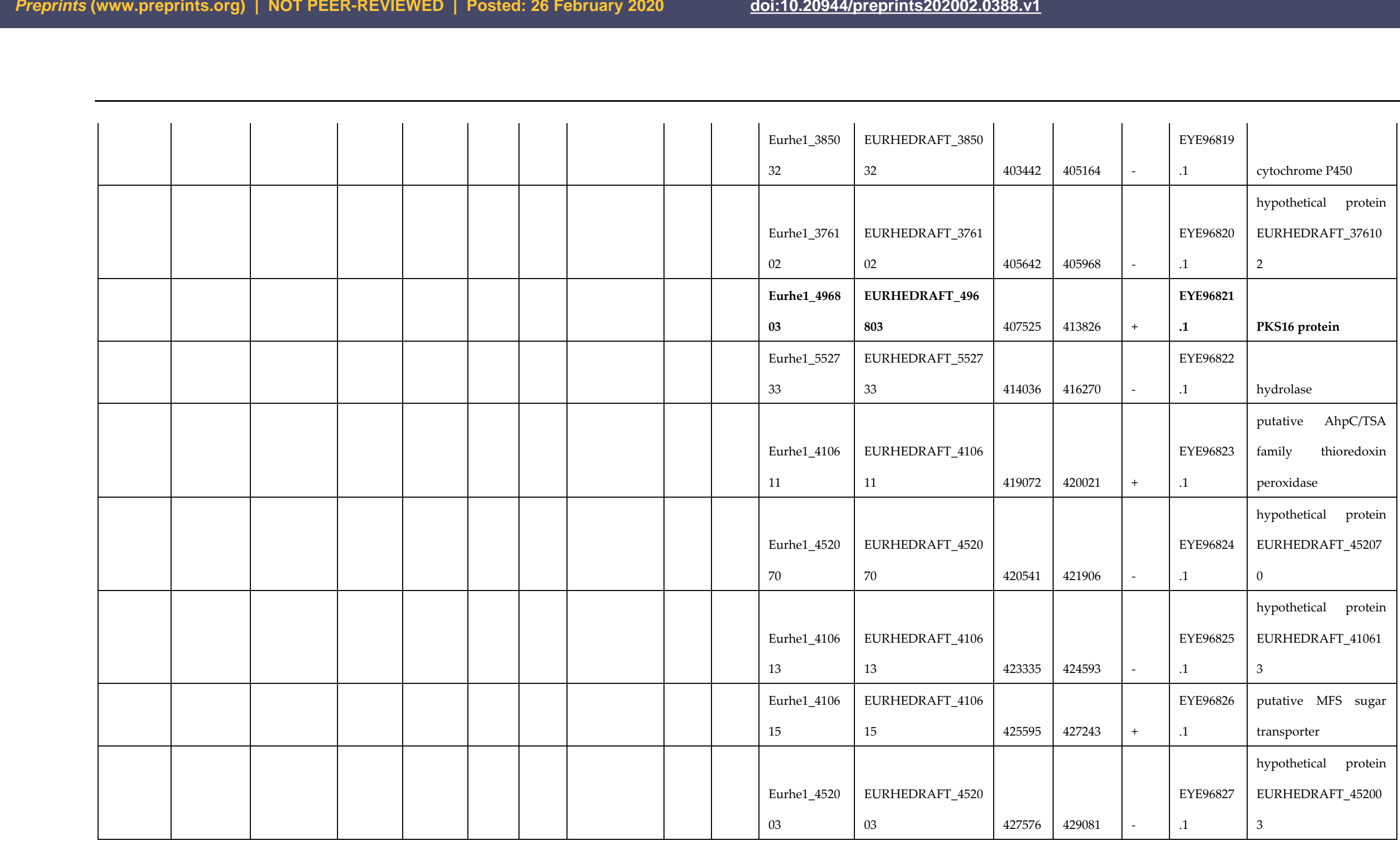




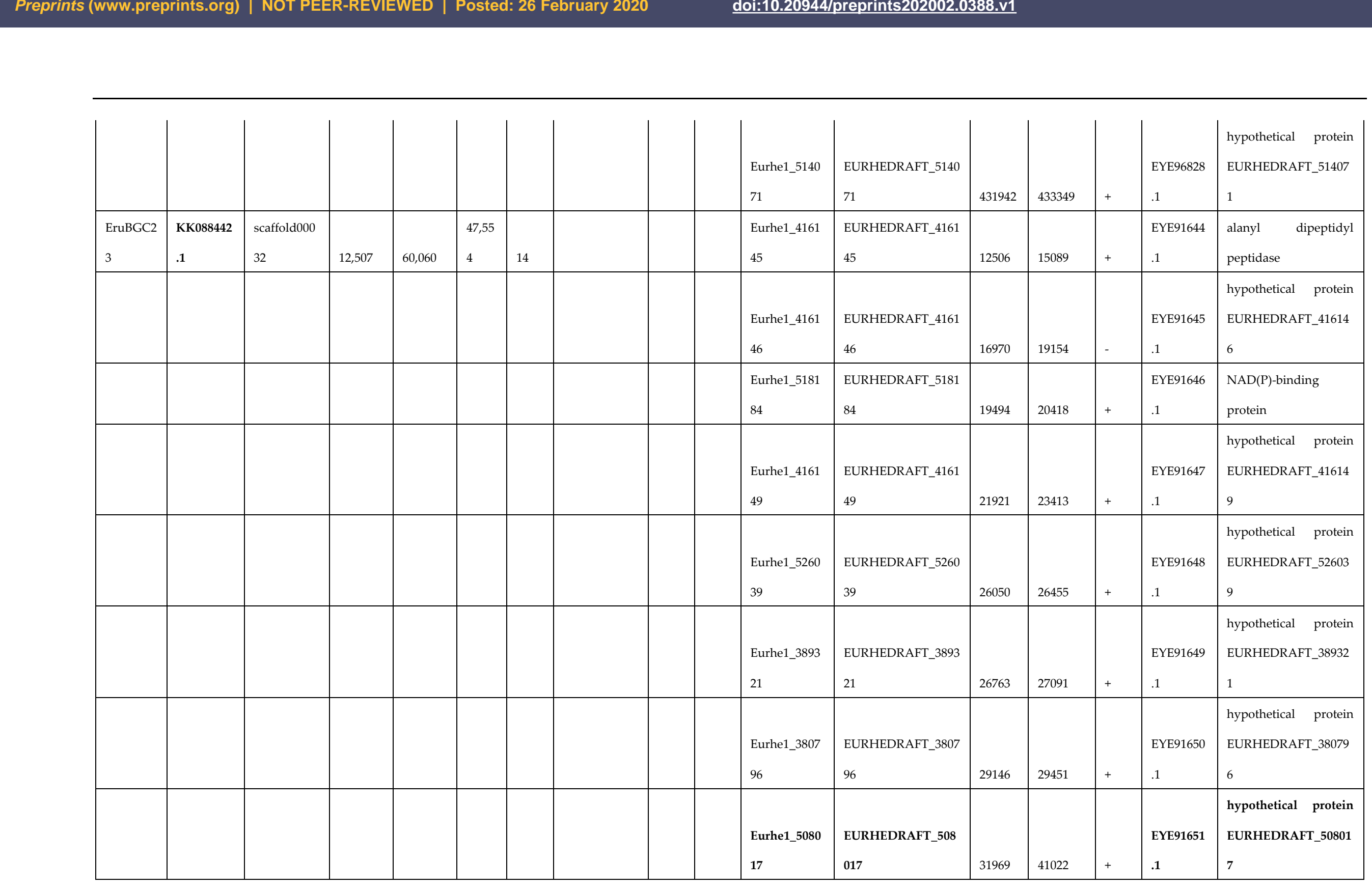




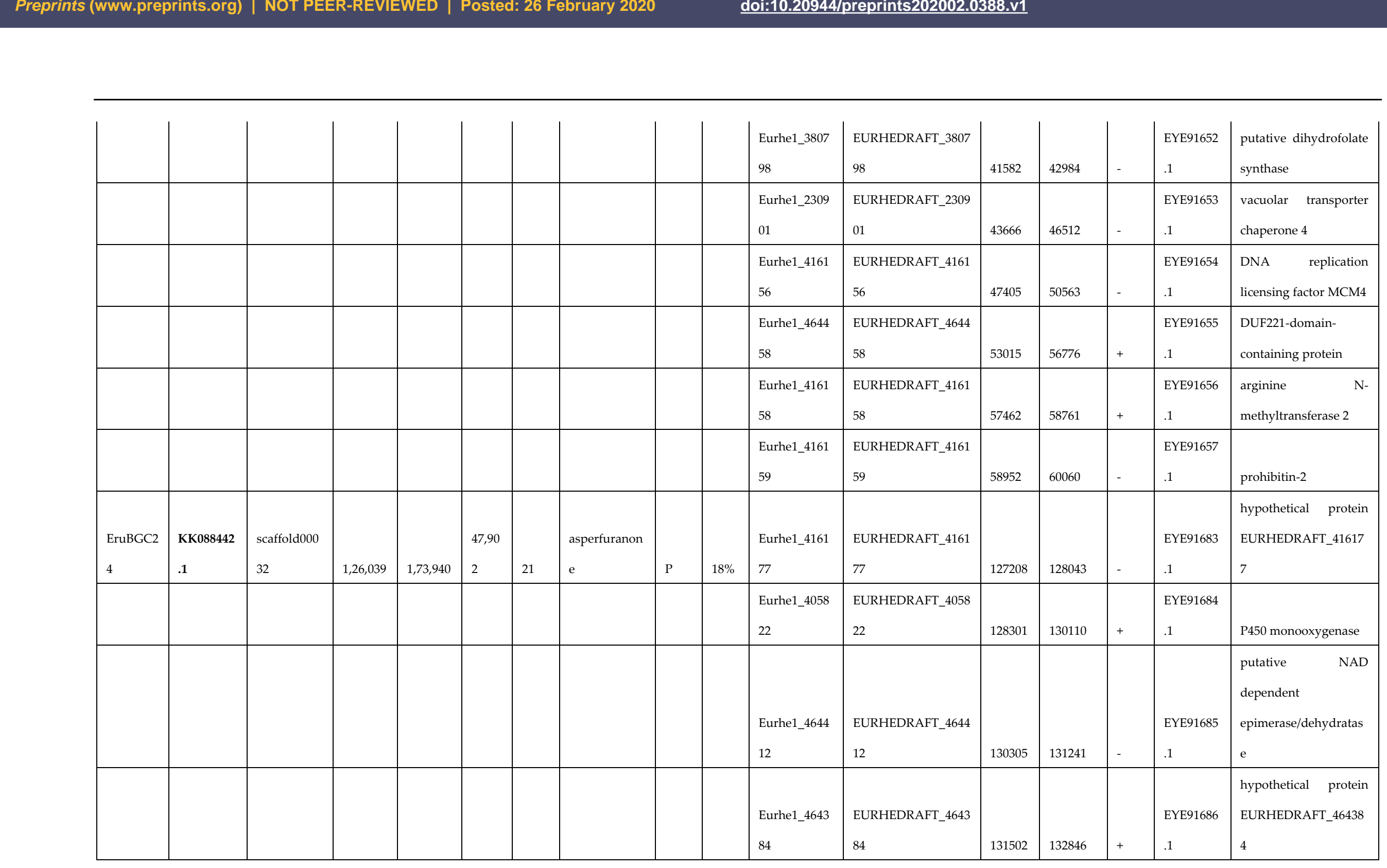




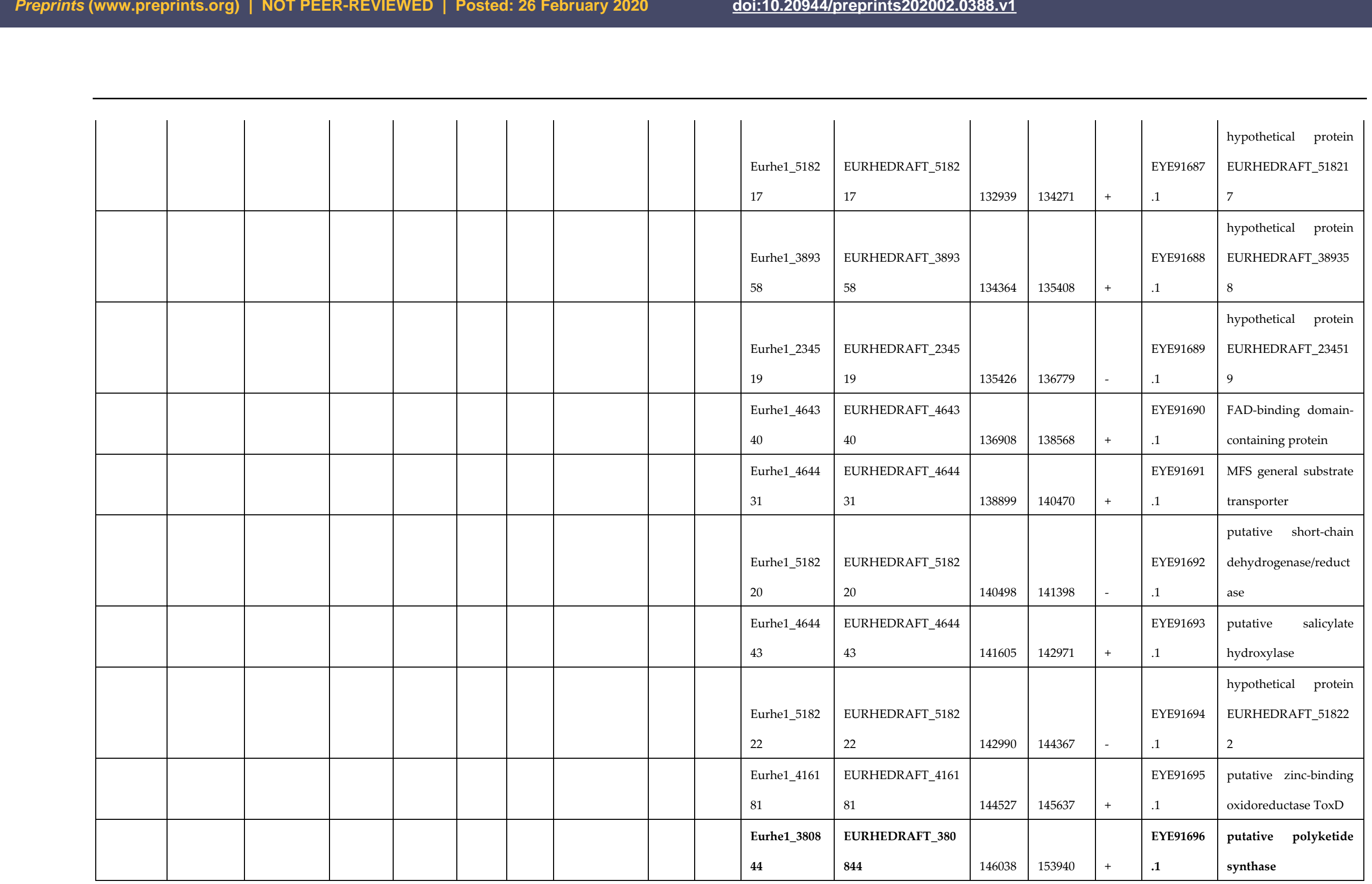




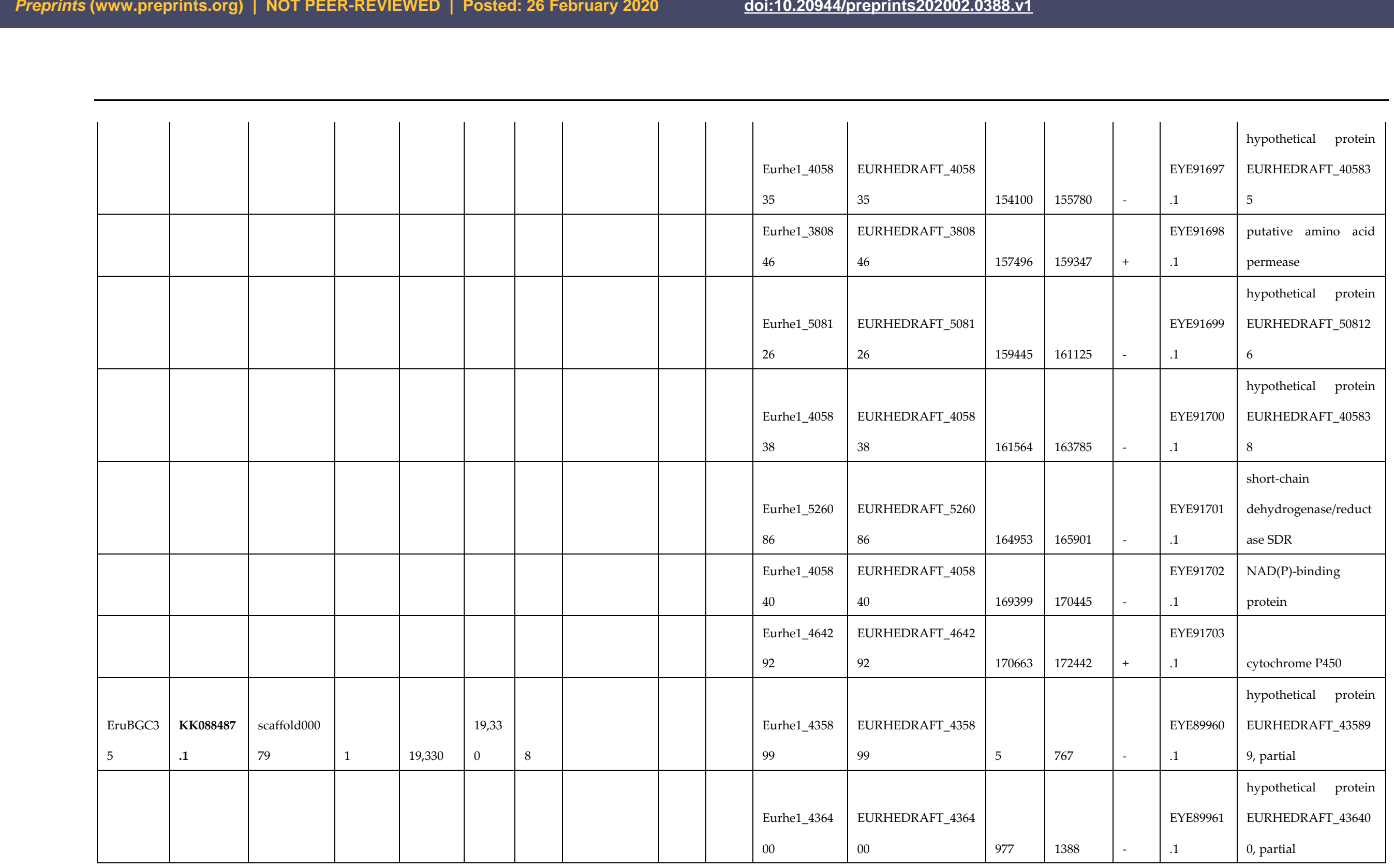




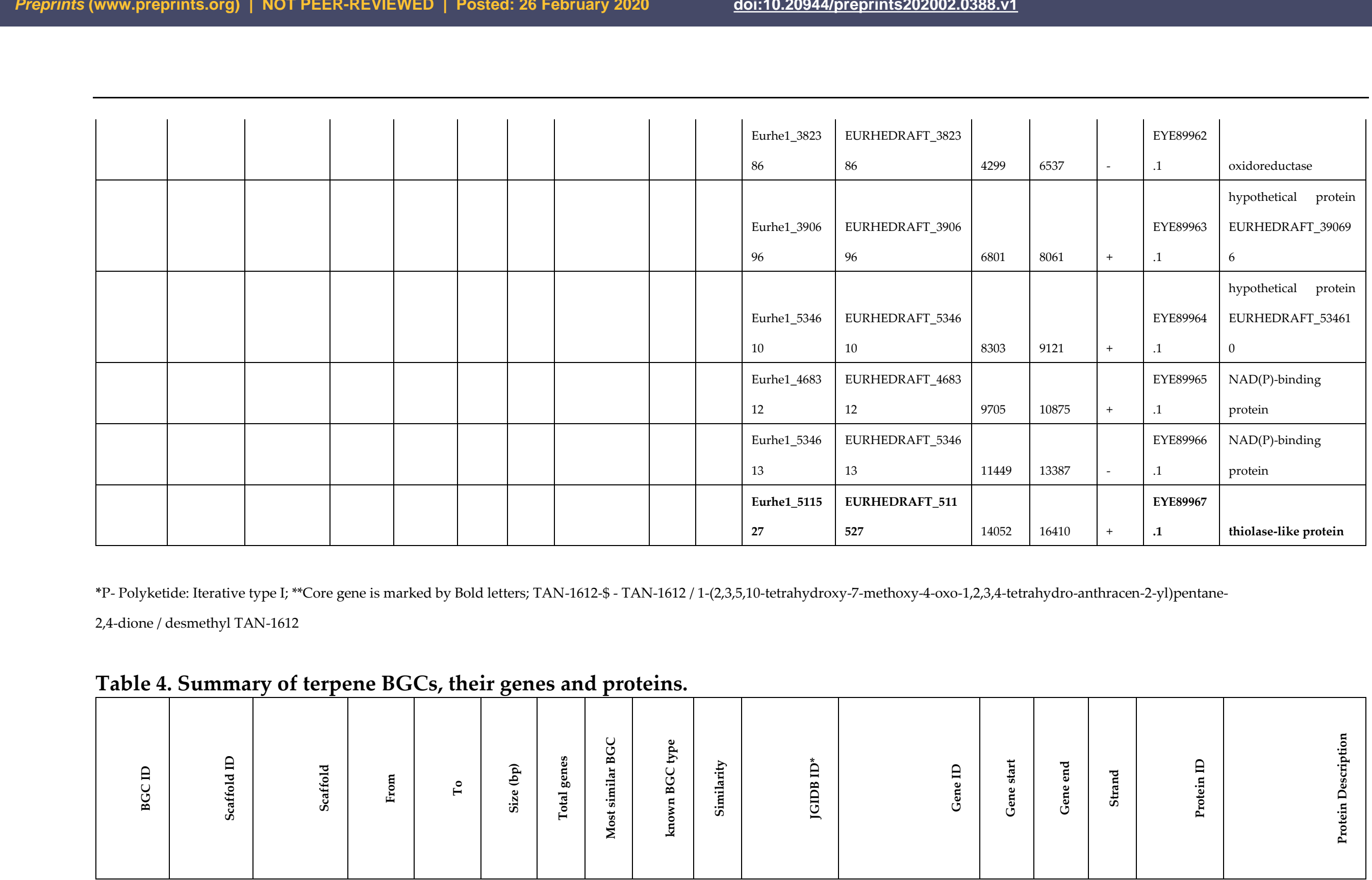

*P- Polyketide: Iterative type I; **Core gene is marked by Bold letters; TAN-1612-\$ - TAN-1612 / 1-(2,3,5,10-tetrahydroxy-7-methoxy-4-oxo-1,2,3,4-tetrahydro-anthracen-2-yl)pentane2,4-dione / desmethyl TAN-1612

Table 4. Summary of terpene BGCs, their genes and proteins.

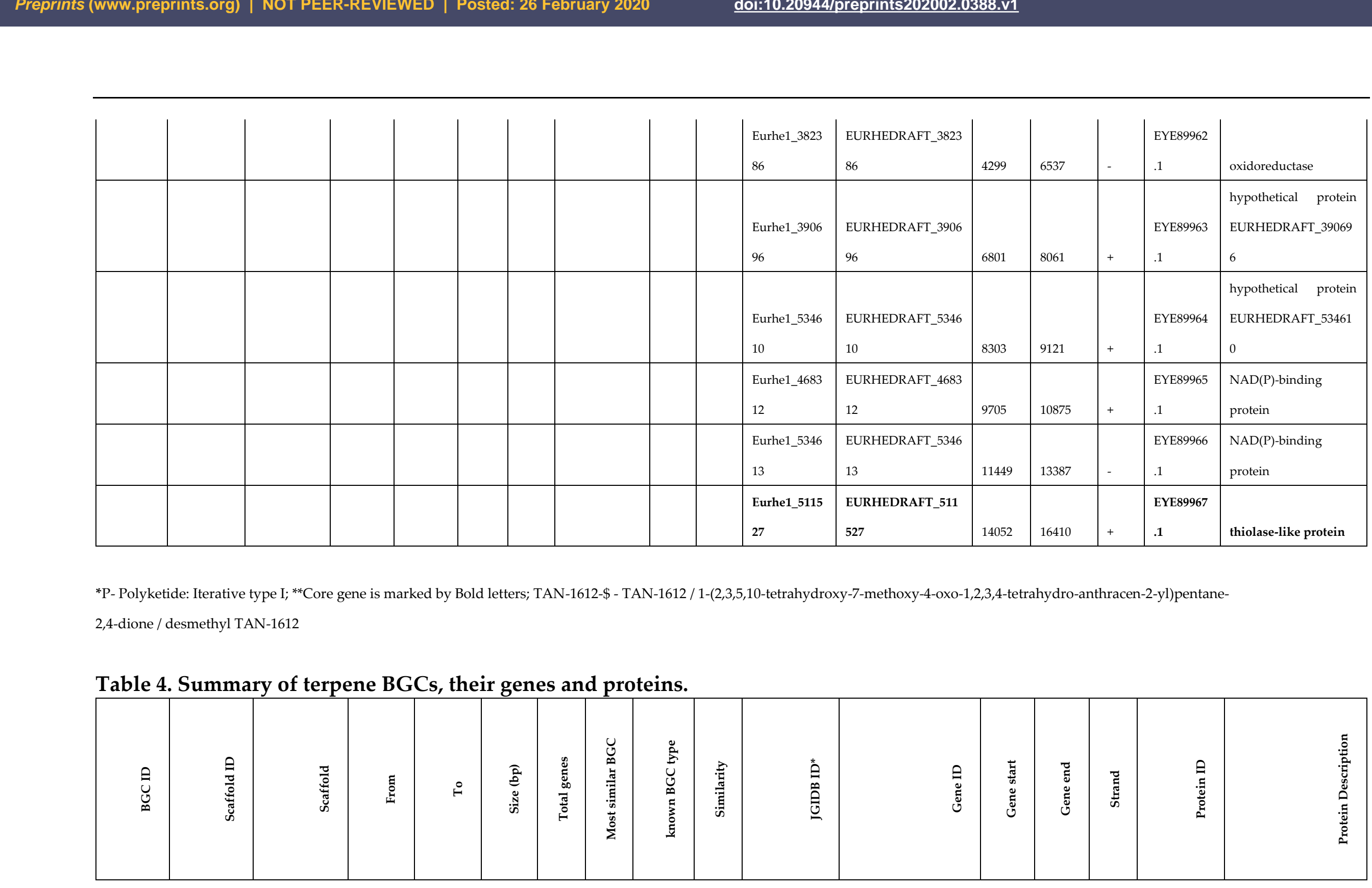




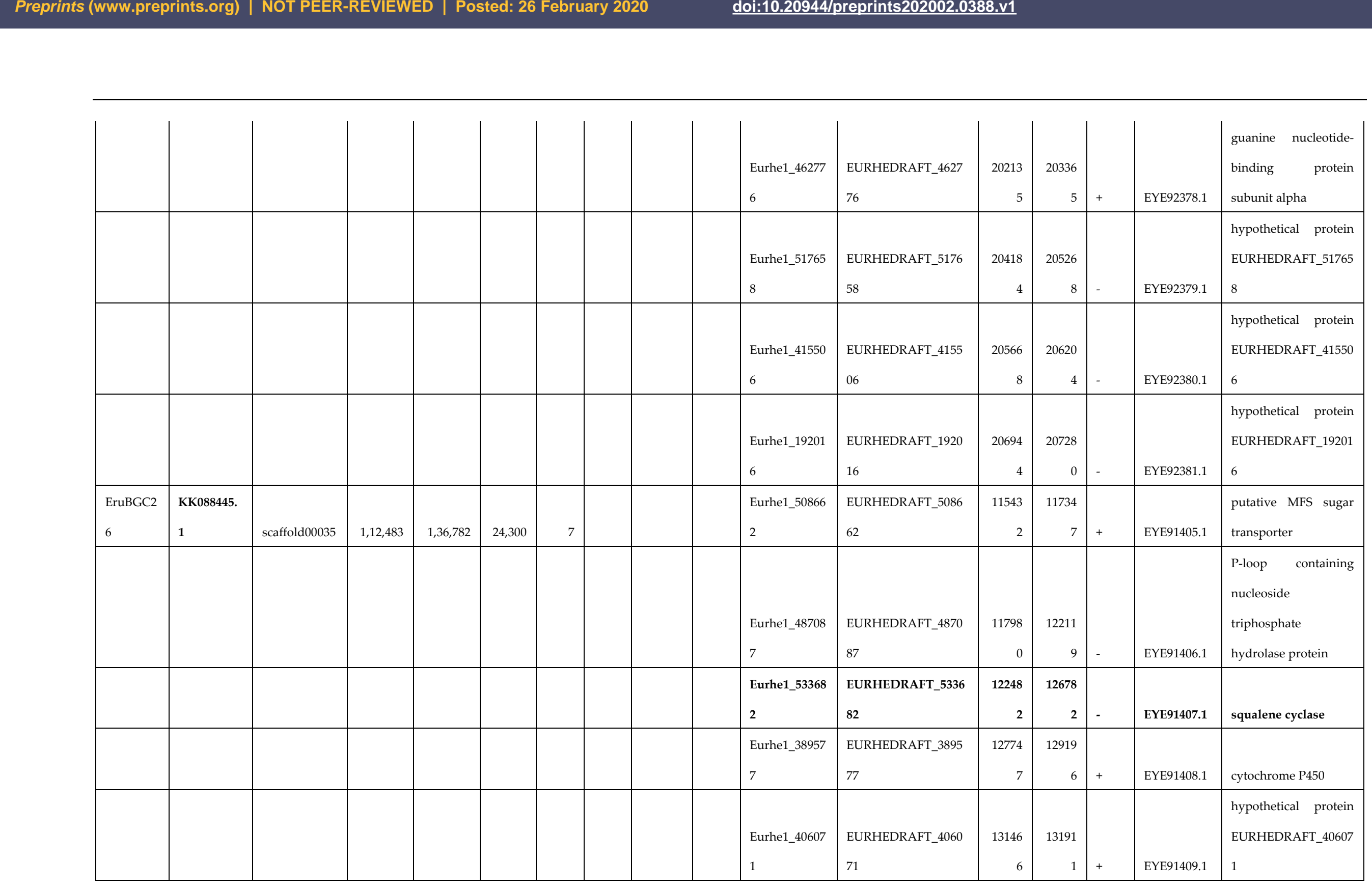




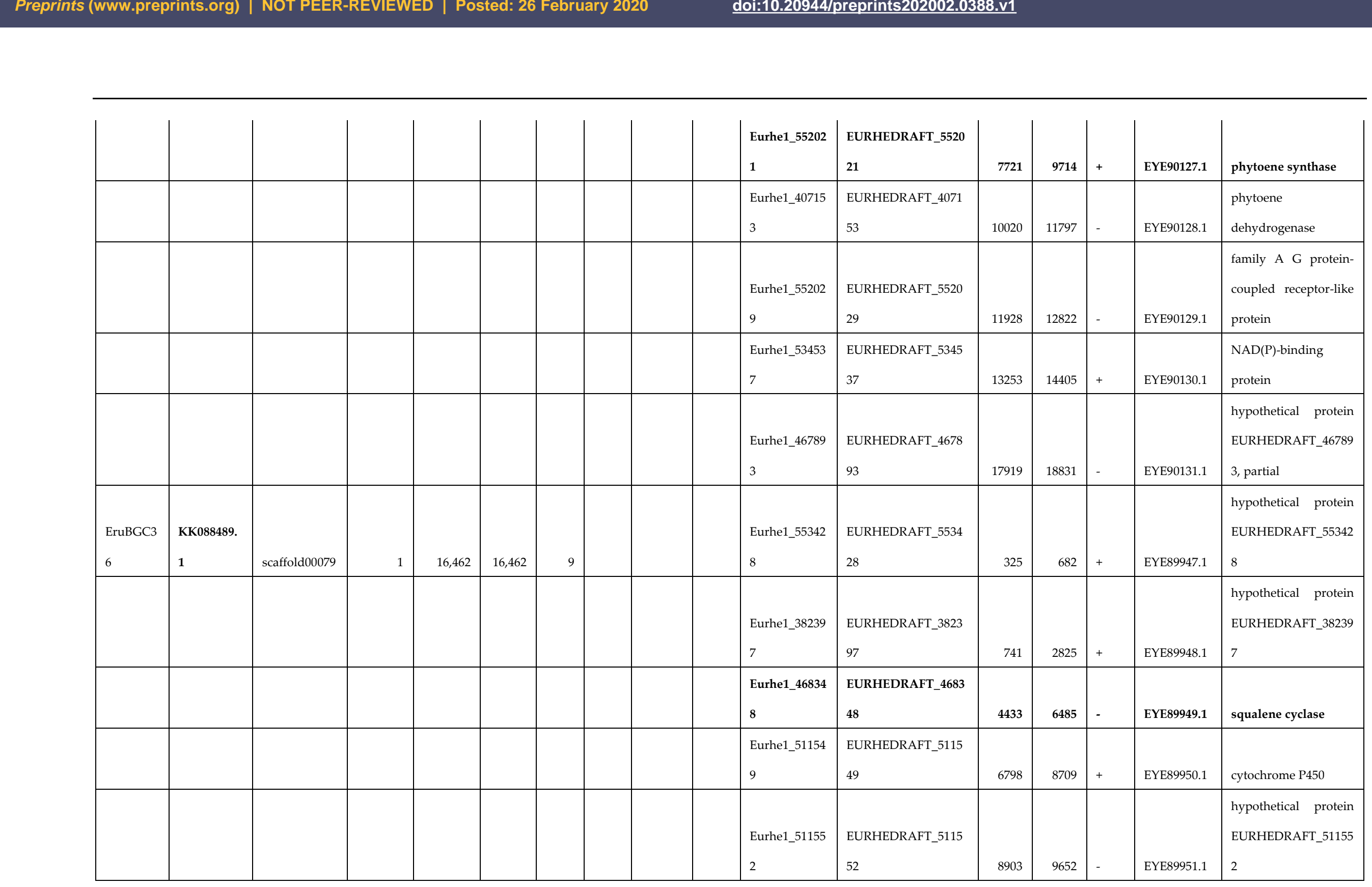




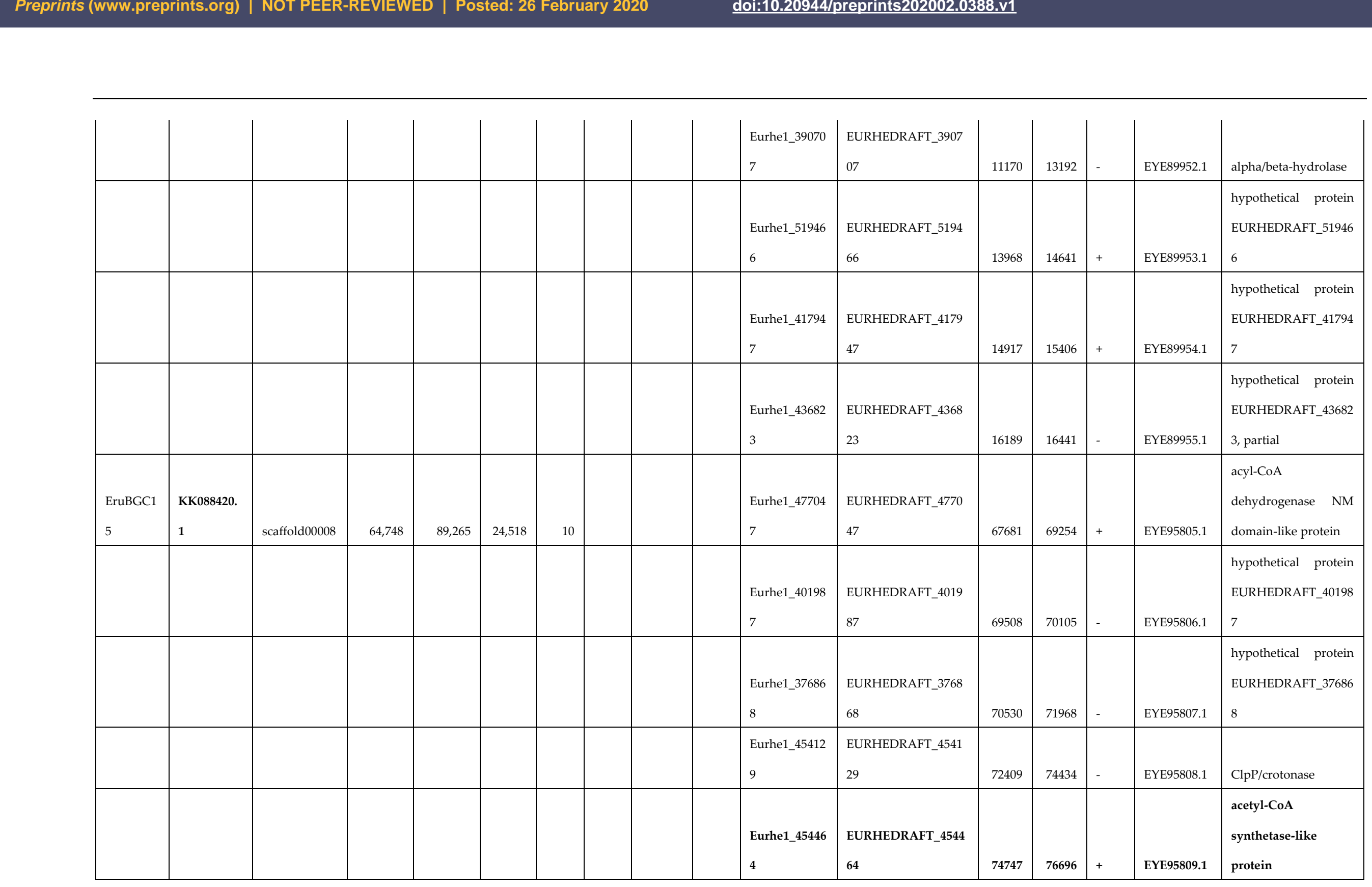




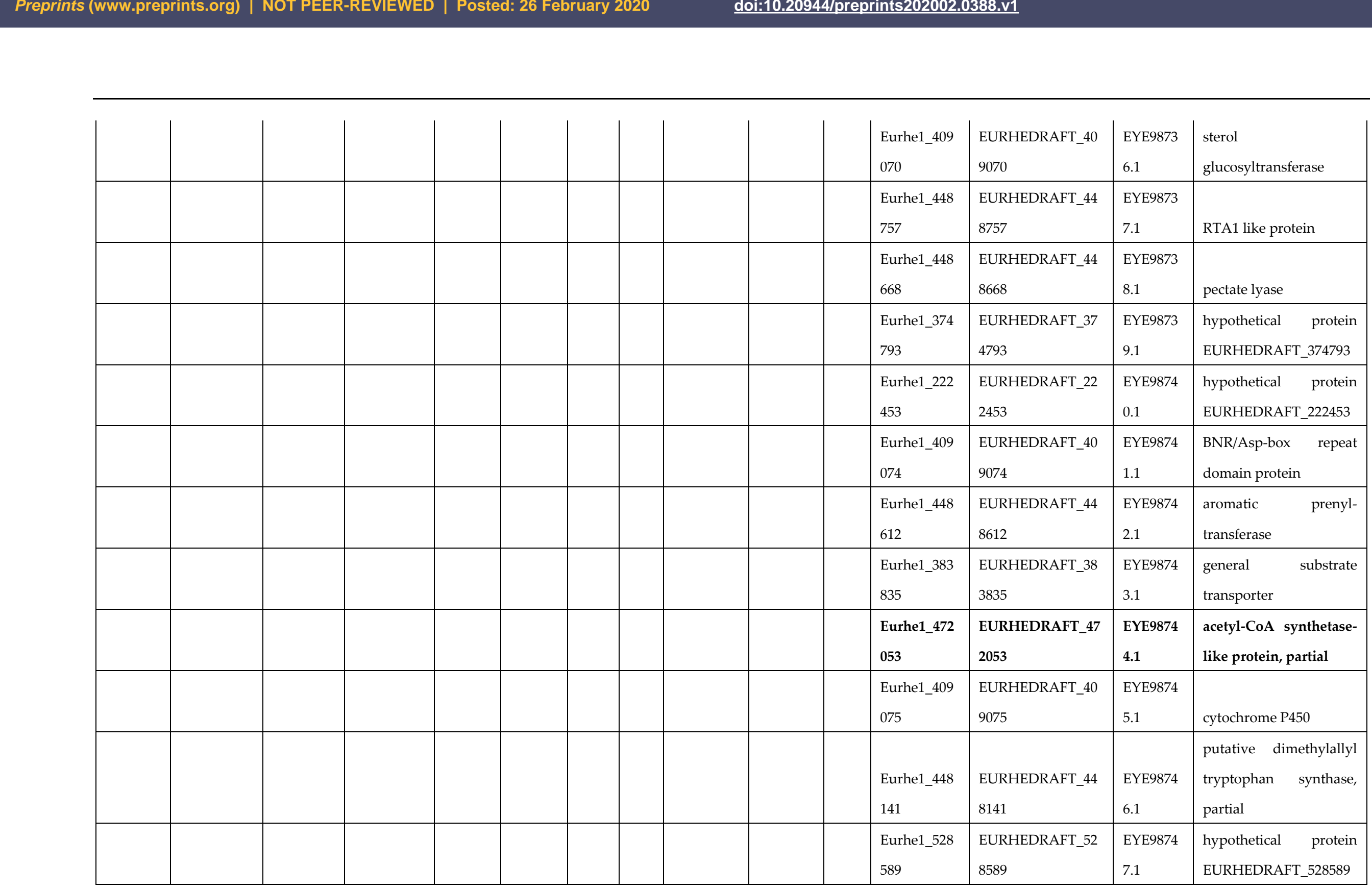




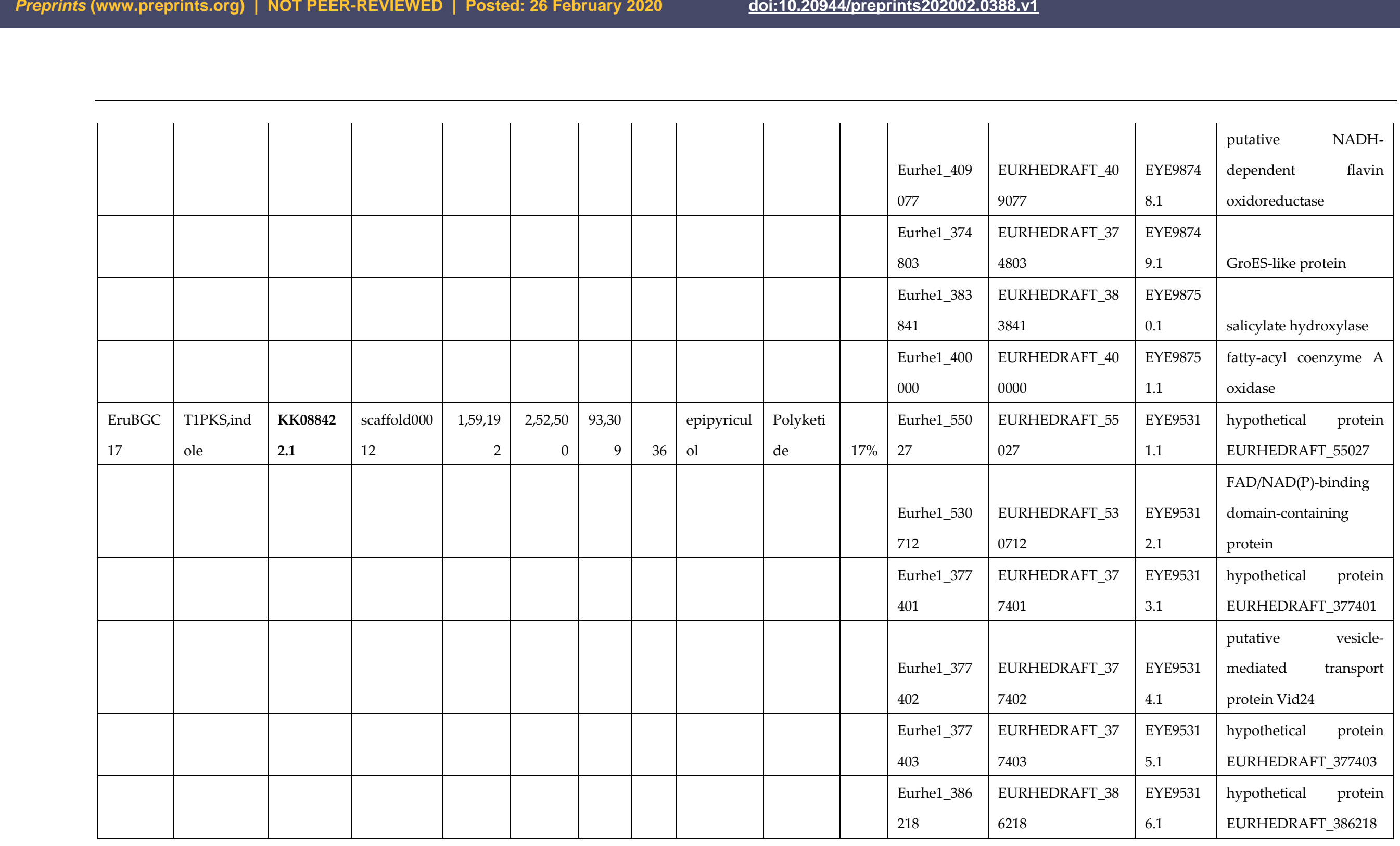




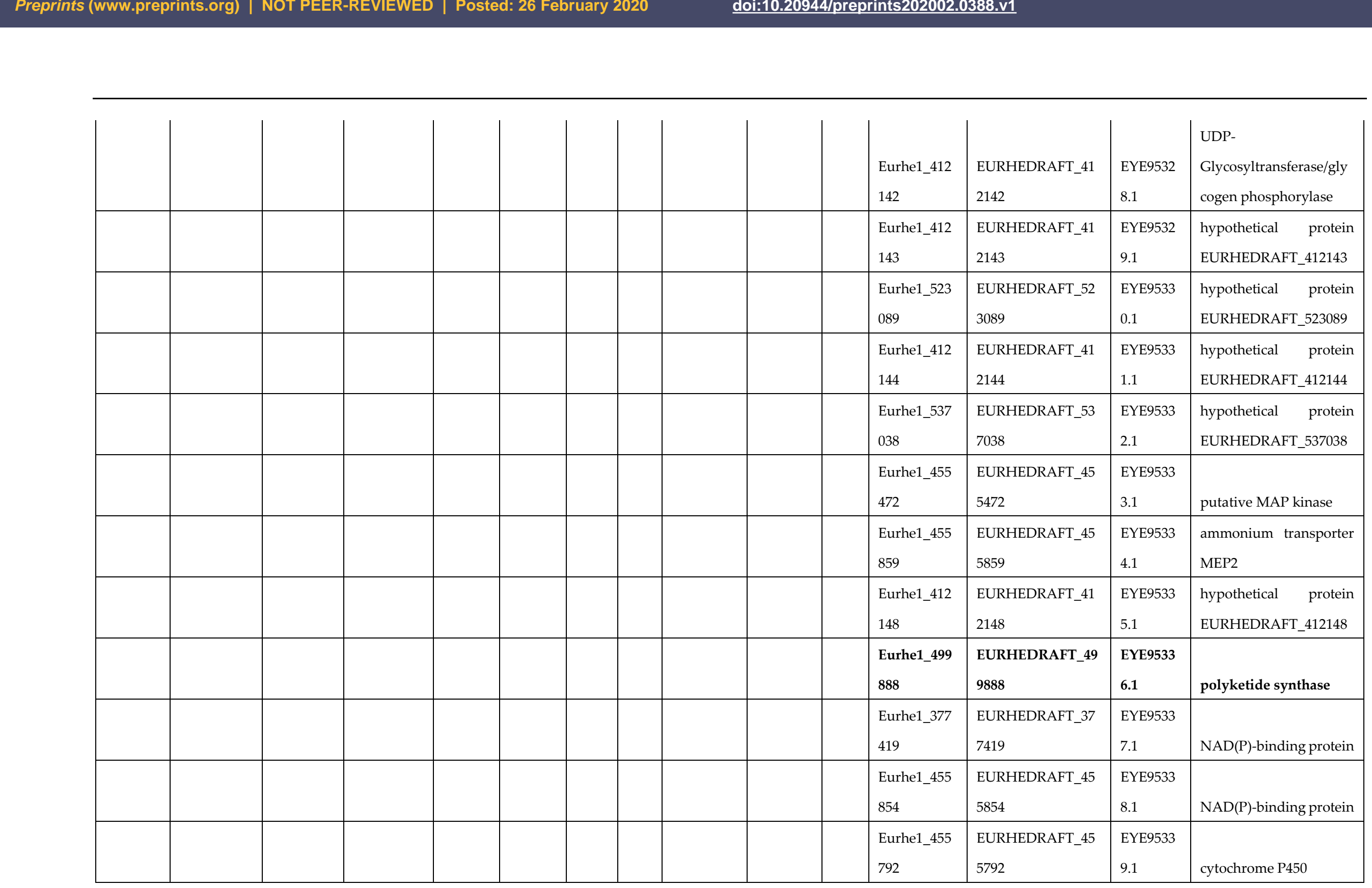




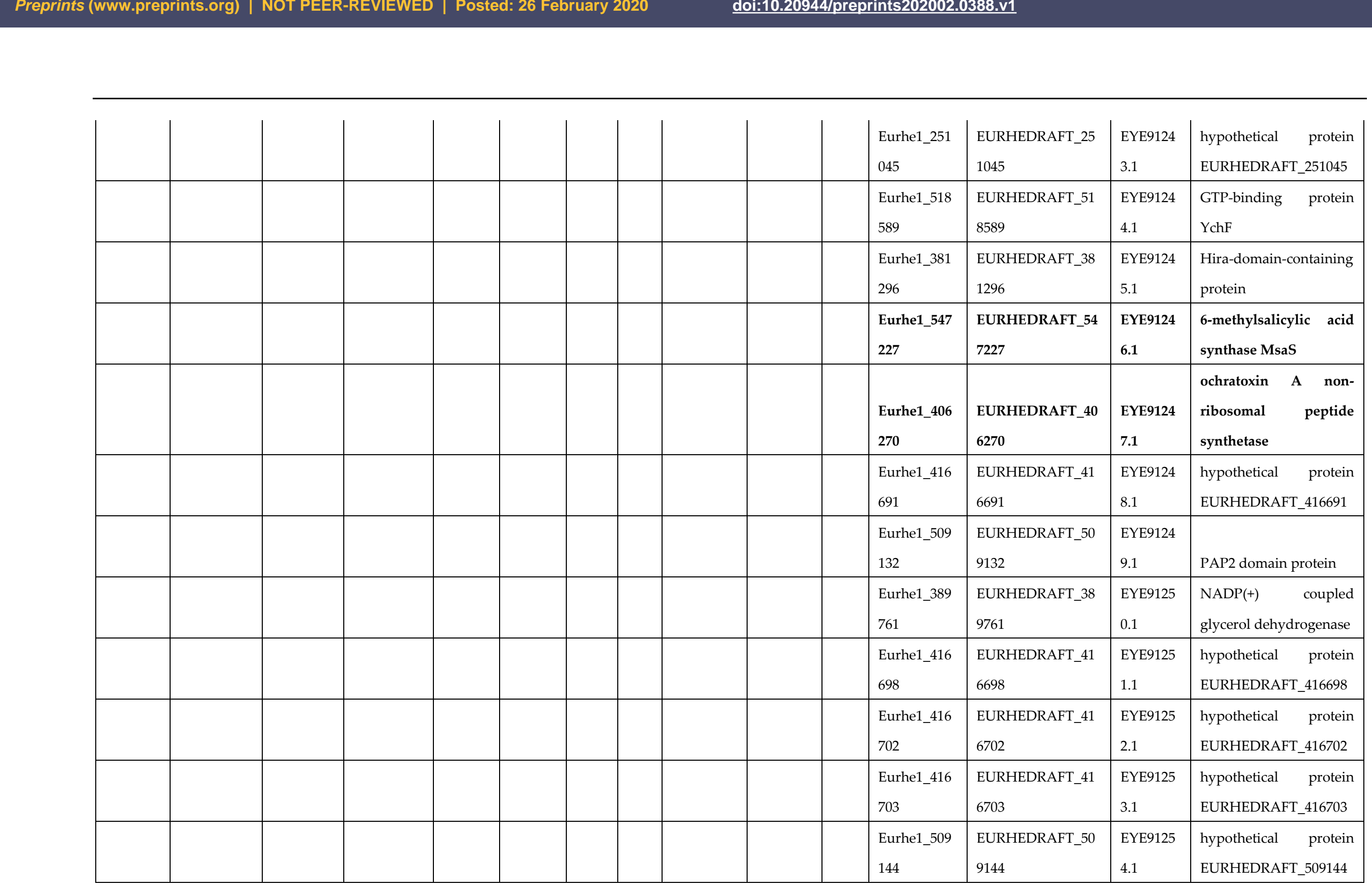




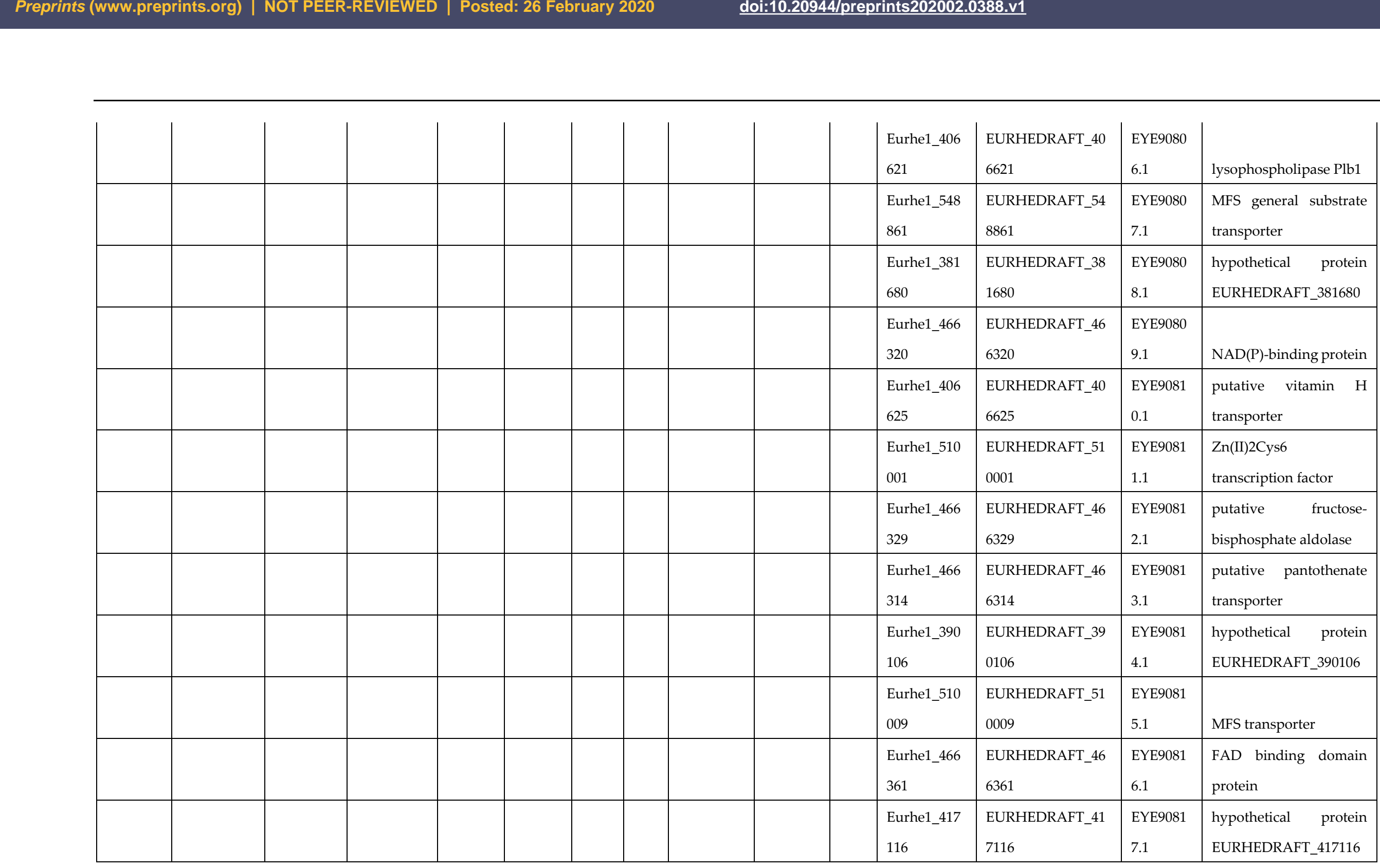




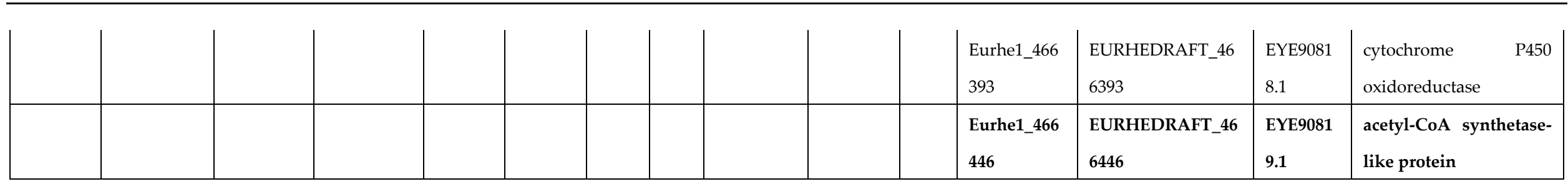

${ }^{*}$ Core gene is marked by Bold letters

Table S6. Overview of siderophore BGCs, their genes and proteins.

\begin{tabular}{|c|c|c|c|c|c|c|c|c|c|c|c|c|c|c|}
\hline 它 & 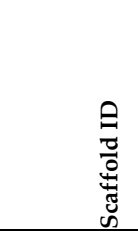 & 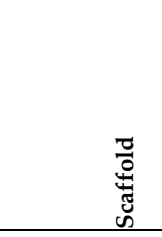 & 总 & $\stackrel{\circ}{\ominus}$ & 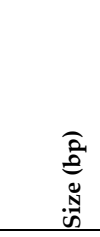 & 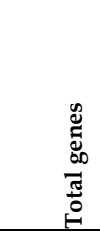 & 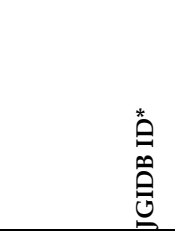 & 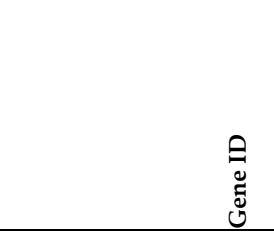 & 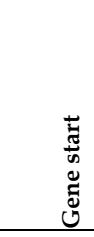 & 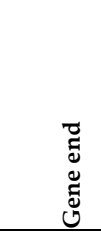 & $\begin{array}{l}\tilde{E} \\
\tilde{\Xi} \\
\text { क }\end{array}$ & 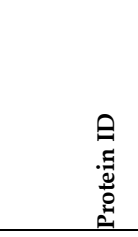 & & 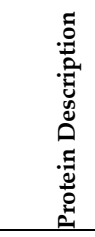 \\
\hline \multirow[t]{2}{*}{ EruBGC9 } & $\begin{array}{l}\text { KK088415. } \\
1\end{array}$ & $\begin{array}{l}\text { scaffold0000 } \\
5\end{array}$ & $1,10,568$ & $1,22,685$ & 12,118 & 2 & $\begin{array}{l}\text { Eurhe1_51333 } \\
5\end{array}$ & $\begin{array}{l}\text { EURHEDRAFT_51333 } \\
5\end{array}$ & 115567 & 117685 & + & $\begin{array}{l}\text { EYE97444. } \\
1\end{array}$ & $\begin{array}{l}\text { hypothetical } \\
\text { EURHEDRAFT_513335 }\end{array}$ & protein \\
\hline & & & & & & & $\begin{array}{l}\text { Eurhe1_52898 } \\
6\end{array}$ & $\begin{array}{l}\text { EURHEDRAFT_52898 } \\
6\end{array}$ & 117755 & 120545 & - & $\begin{array}{l}\text { EYE97445. } \\
1\end{array}$ & $\begin{array}{l}\text { hypothetical } \\
\text { EURHEDRAFT_528986 }\end{array}$ & protein \\
\hline \multirow[t]{5}{*}{$\begin{array}{l}\text { EruBGC1 } \\
2\end{array}$} & $\begin{array}{l}\text { KK088417. } \\
1\end{array}$ & $\begin{array}{l}\text { scaffold } 0000 \\
7\end{array}$ & $3,72,420$ & $3,84,556$ & 12,137 & 5 & $\begin{array}{l}\text { Eurhe1_52964 } \\
7\end{array}$ & $\begin{array}{l}\text { EURHEDRAFT_52964 } \\
7\end{array}$ & 374939 & 376088 & - & $\begin{array}{l}\text { EYE96807. } \\
1\end{array}$ & \multicolumn{2}{|c|}{ Clavaminate synthase-like protein } \\
\hline & & & & & & & $\begin{array}{l}\text { Eurhe1_51405 } \\
1\end{array}$ & $\begin{array}{l}\text { EURHEDRAFT_51405 } \\
1\end{array}$ & 377419 & 379556 & + & $\begin{array}{l}\text { EYE96808. } \\
1\end{array}$ & $\begin{array}{l}\text { hypothetical } \\
\text { EURHEDRAFT_514051 }\end{array}$ & protein \\
\hline & & & & & & & $\begin{array}{l}\text { Eurhe1_37609 } \\
4\end{array}$ & $\begin{array}{l}\text { EURHEDRAFT_37609 } \\
4\end{array}$ & 379629 & 380190 & - & $\begin{array}{l}\text { EYE96809. } \\
1\end{array}$ & $\begin{array}{l}\text { hypothetical } \\
\text { EURHEDRAFT_376094 }\end{array}$ & protein \\
\hline & & & & & & & $\begin{array}{l}\text { Eurhe1_55268 } \\
5\end{array}$ & $\begin{array}{l}\text { EURHEDRAFT_55268 } \\
5\end{array}$ & 380375 & 381109 & - & $\begin{array}{l}\text { EYE96810. } \\
1\end{array}$ & $\begin{array}{l}\text { hypothetical } \\
\text { EURHEDRAFT_552685 }\end{array}$ & protein \\
\hline & & & & & & & $\begin{array}{l}\text { Eurhe1_41059 } \\
6\end{array}$ & $\begin{array}{l}\text { EURHEDRAFT_41059 } \\
6\end{array}$ & 383661 & 384519 & - & $\begin{array}{l}\text { EYE96811. } \\
1\end{array}$ & $\begin{array}{l}\text { hypothetical } \\
\text { EURHEDRAFT_410596 }\end{array}$ & protein \\
\hline
\end{tabular}


${ }^{*}$ Core gene is marked by Bold letter.

\author{
-
}

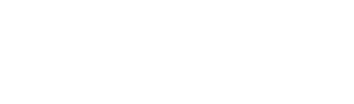

$\left(\frac{100}{20}\right.$

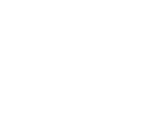

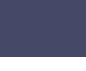
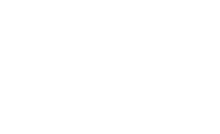